Gotong Royong Membumikan Inovasi Teknologi ala Jerman

HENDRO WICAKSONO

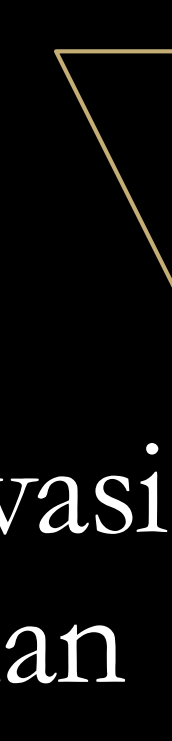


I. Introduction: Innovation and German Economy

II. Research and Innovation Landscape in Germany

Contents

III. Implementation of TripleHelix Innovation in Germany

IV. Examples of Research and Innovation Project Collaborations 


\section{What is Innovation?}

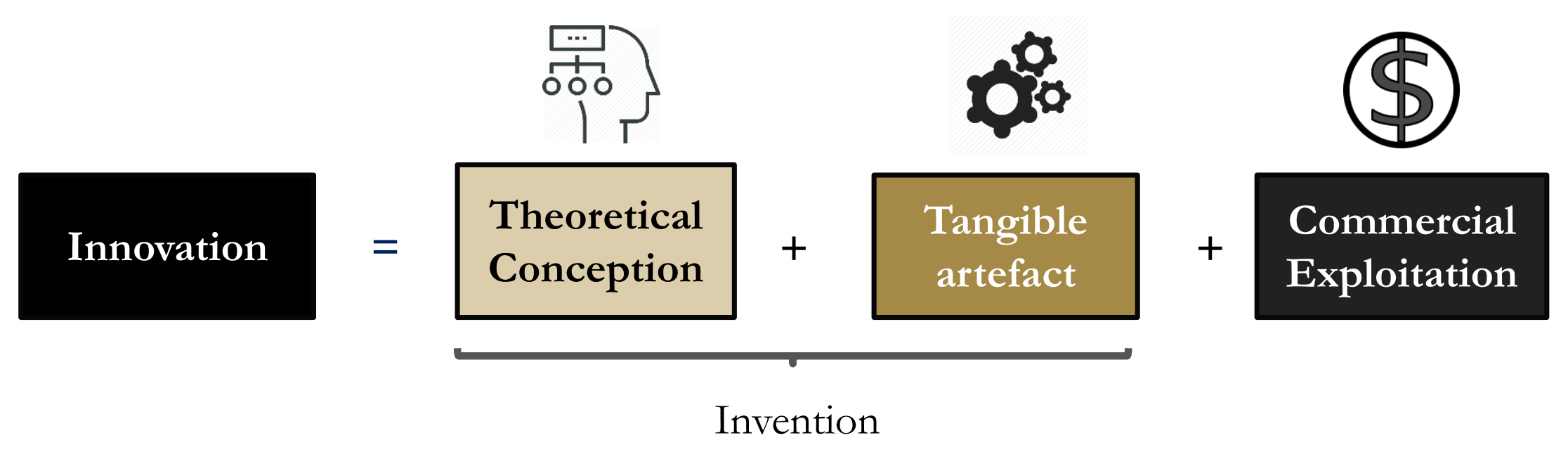




\section{Innovation 4P}

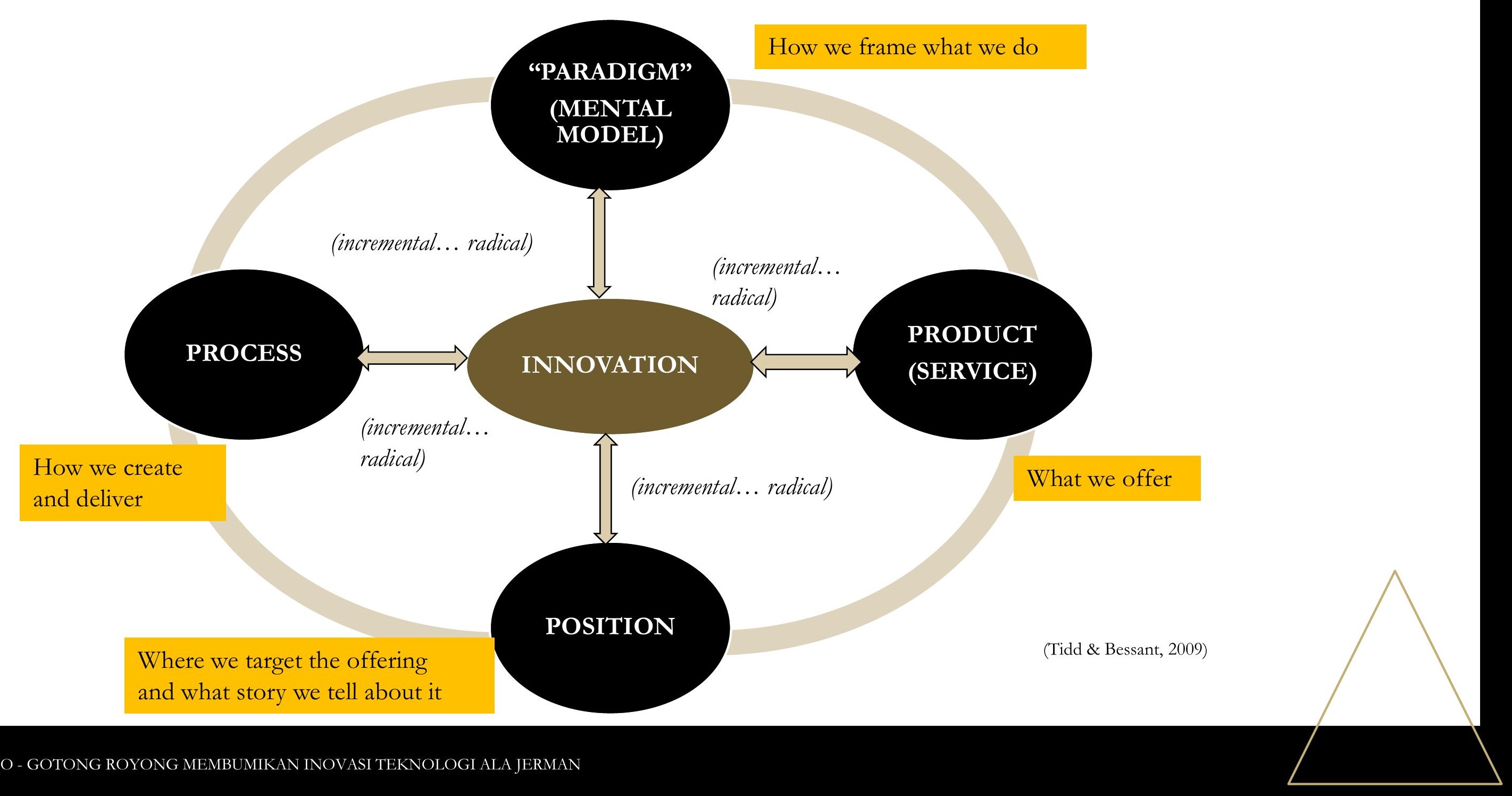




\section{Where do innovations come from?}
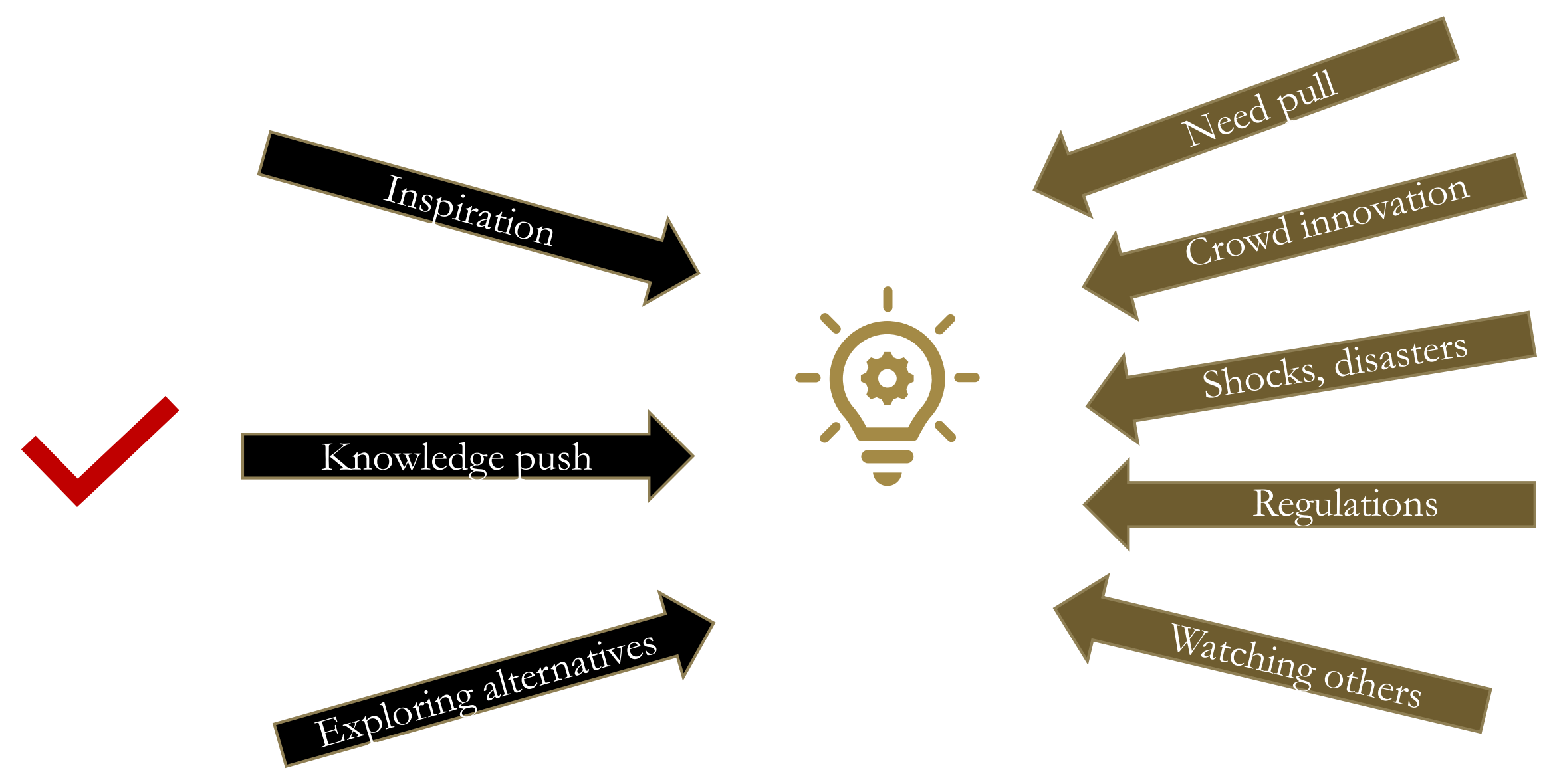


\section{Closed vs. Open innovation}
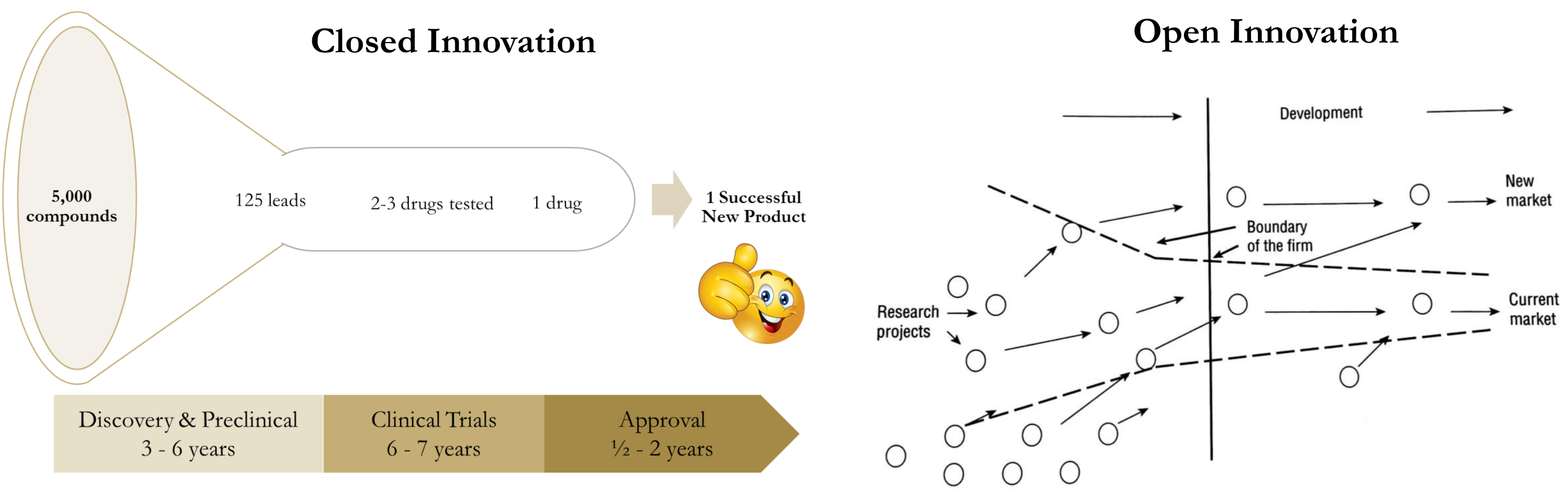


\section{The German Social Market Economv}

MANAGEMENT MODEL "MADE IN GERMANY"

- Free market + social-oriented policies $=$ welfare state

- A middle way between liberalism and capitalism

- Inspiration: ordoliberalism + social democracy + Christian ethics

Hidden Champions

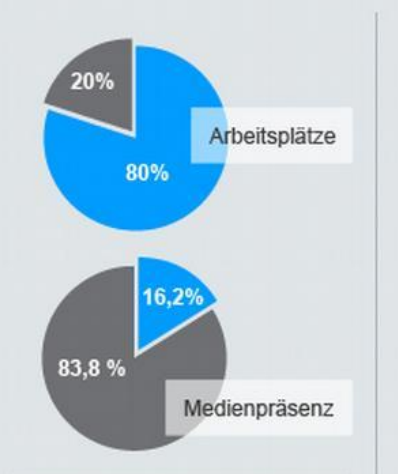

Großunternehmen - Kleine u. mittlere Unternehmen

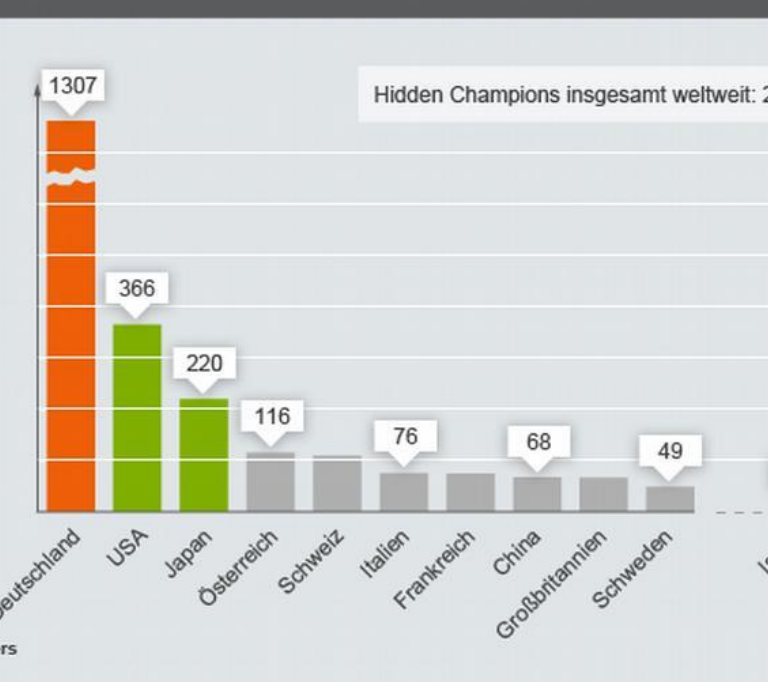

MITTELSTAND COMPANIES AS SPEARHEAD OF GERMANY'S SUCCESS IN EXPORTS

Quelle: Wachstum D, Simon Kucher \& Parthers
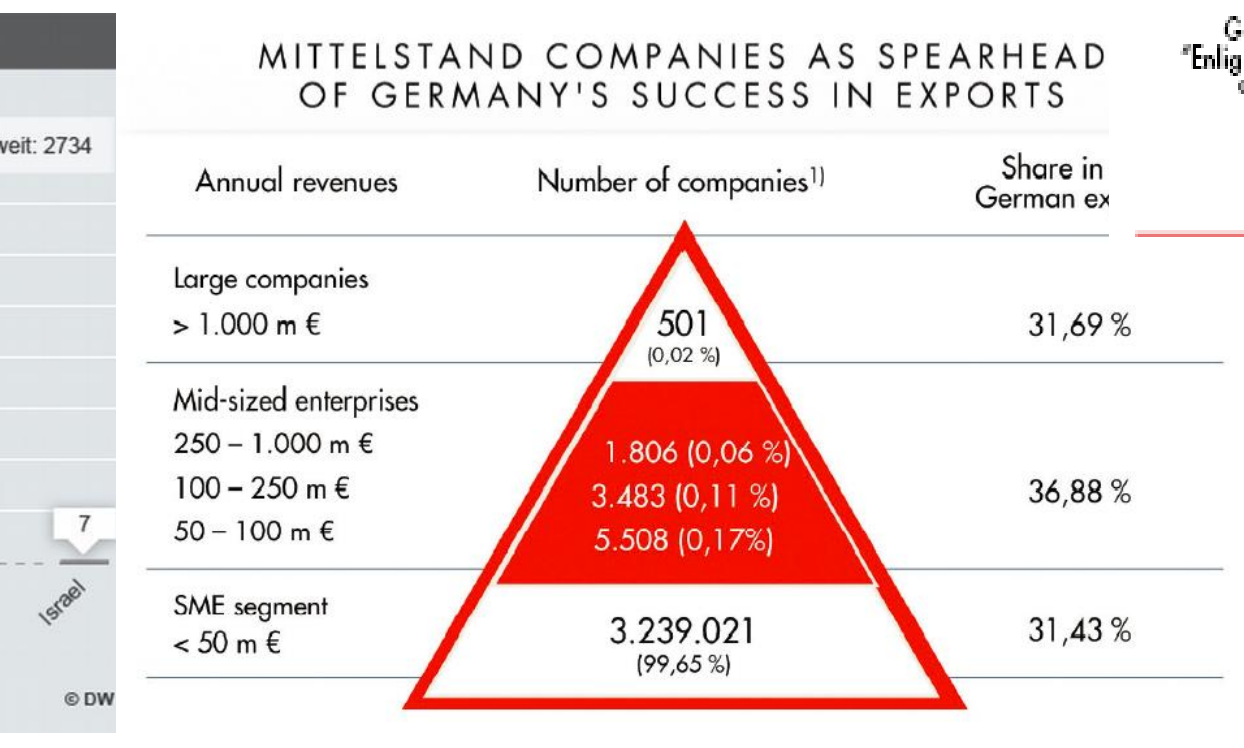

DANAG

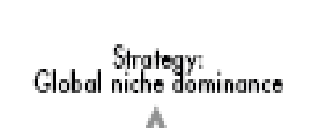

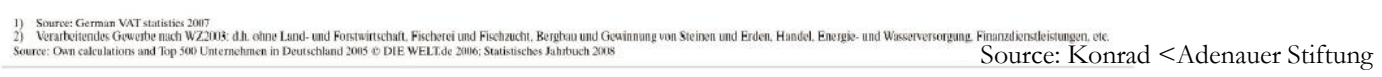
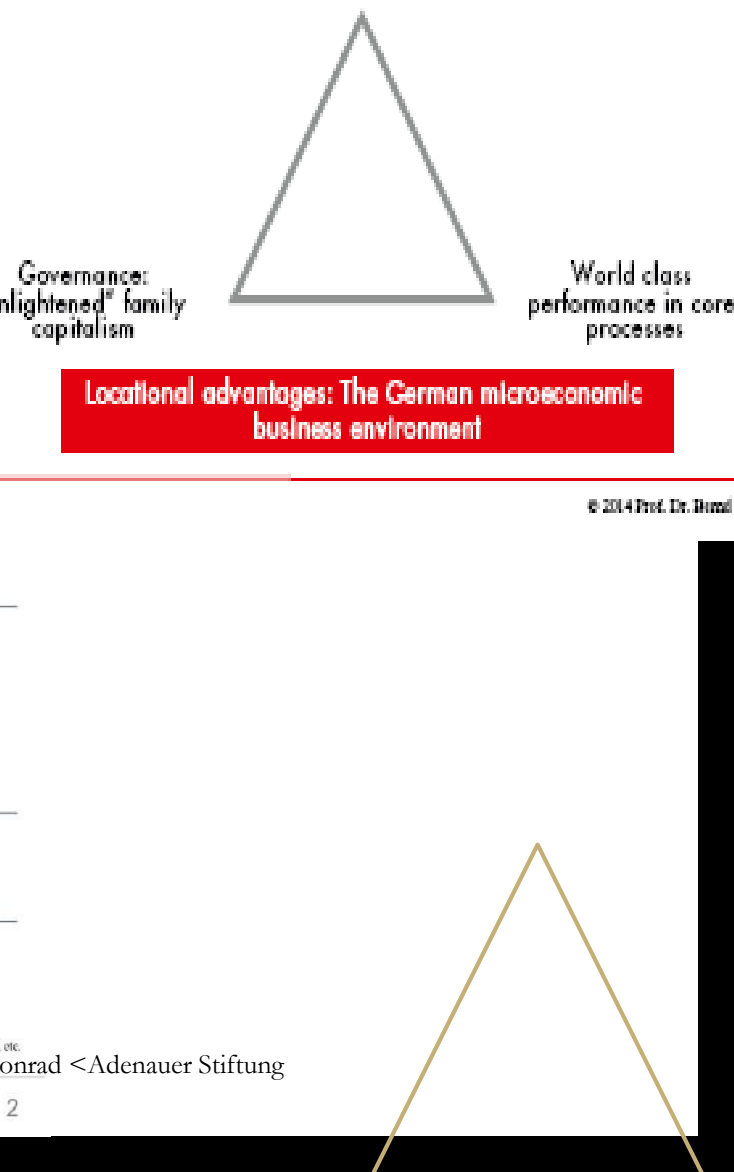
Locatlonal advantages: The German microeconomic
business environment

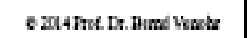

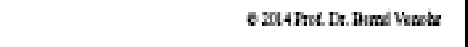




\section{Example of ongoing innovations made in}

\section{Germany}

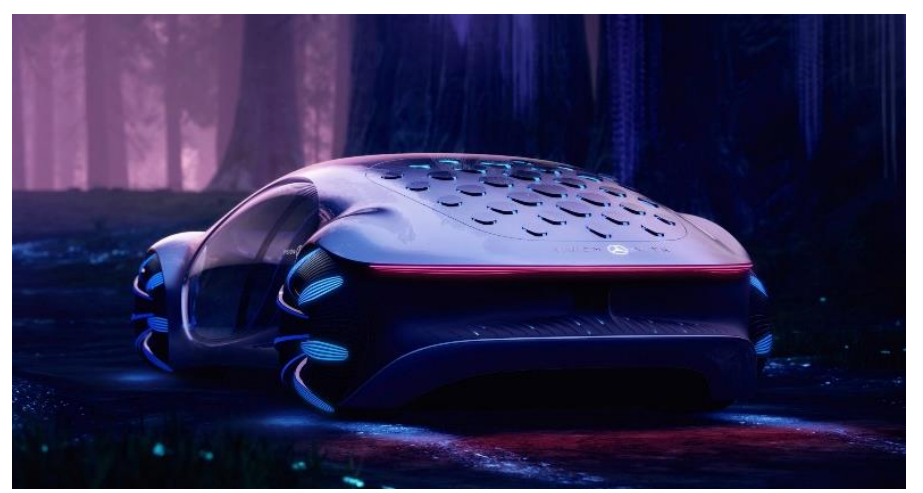

Daimler meets Avatar

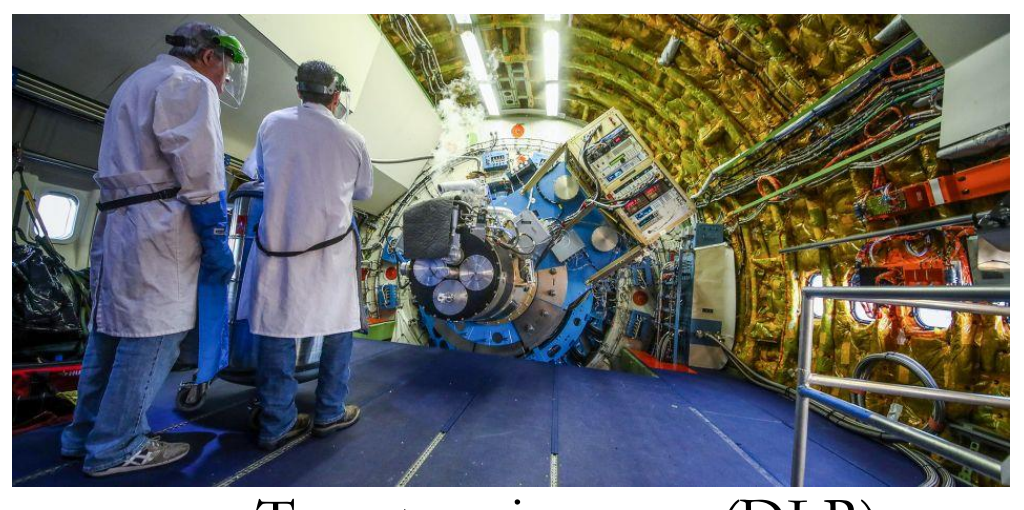

Tomatoes in space (DLR)

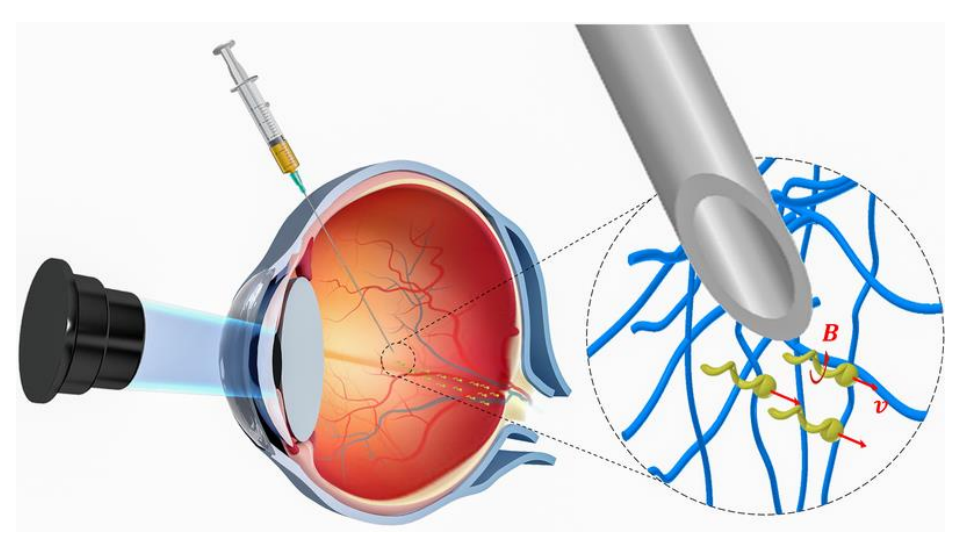

Nanorobot in the Body (Max Planck)

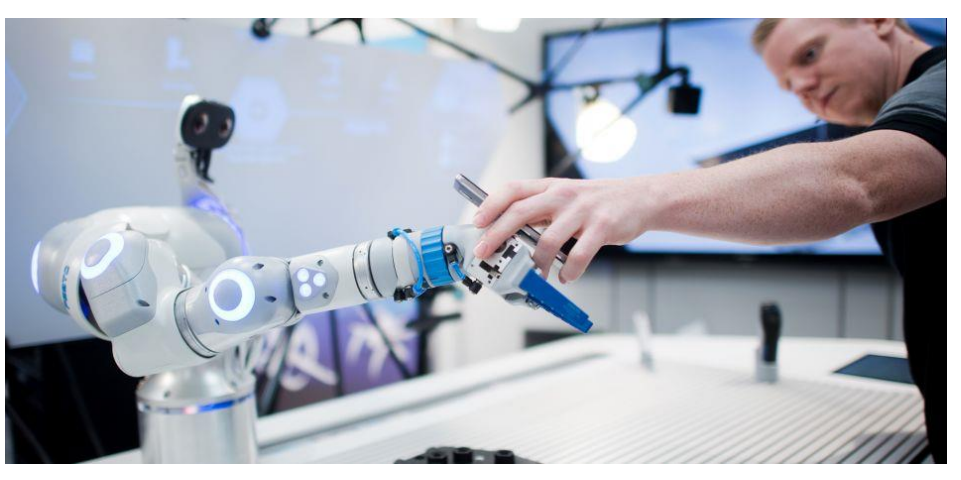

Digital twin, human-robot collabs

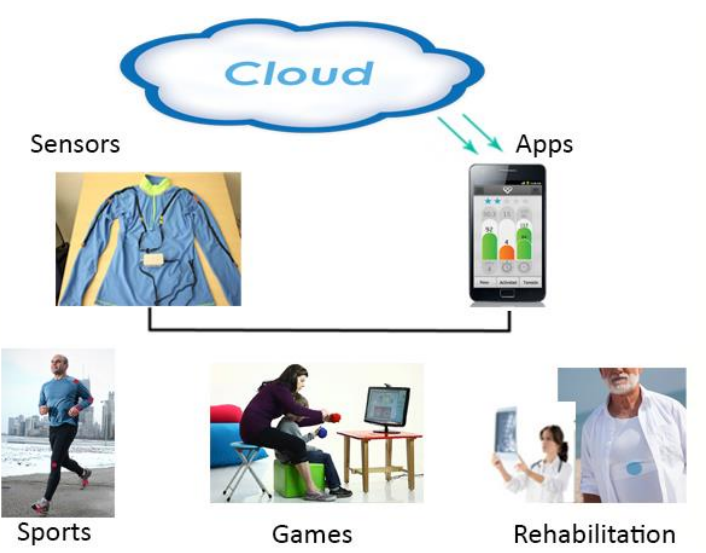

Personalized meta products 


\section{Research in Germany}

\section{GERMAN R\&D UNDER THE MICROSCOPE}

A self-ranked assessment of how public and private research organizations in Germany are funded and their research priorities.

\section{RESEARCHER RANKINGS}

Germany has the highest number of researchers working in science

and technology industries and academia in the European Union.

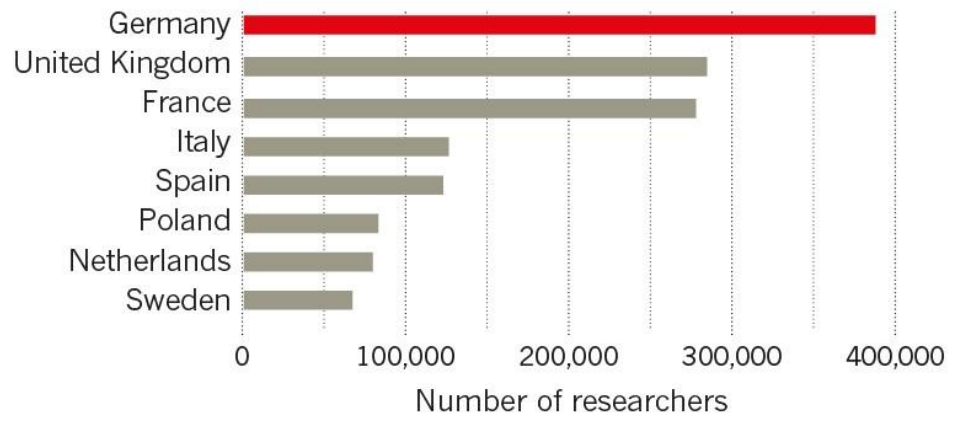

\section{THE GERMAN GOVERNMENT LOVES SCIENCE}

In 2016, researchers working across the natural sciences received

more funding than those in other academic disciplines.

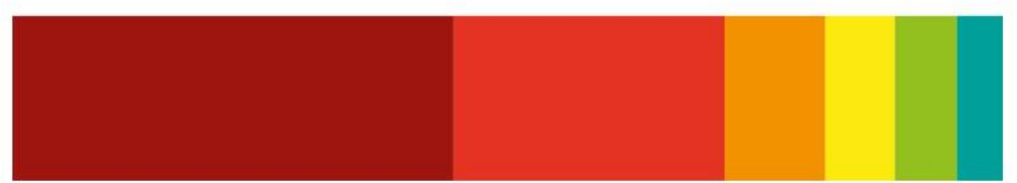

Natural sciences $€ 5.7$ billion

Engineering \& technology $€ 3.5$ billion

- Medical \& health sciences $€ 1.3$ billion

Humanities $€ 0.9$ billion

- Social sciences $€ 0.8$ billion

Agricultural sciences $€ 0.6$ billion

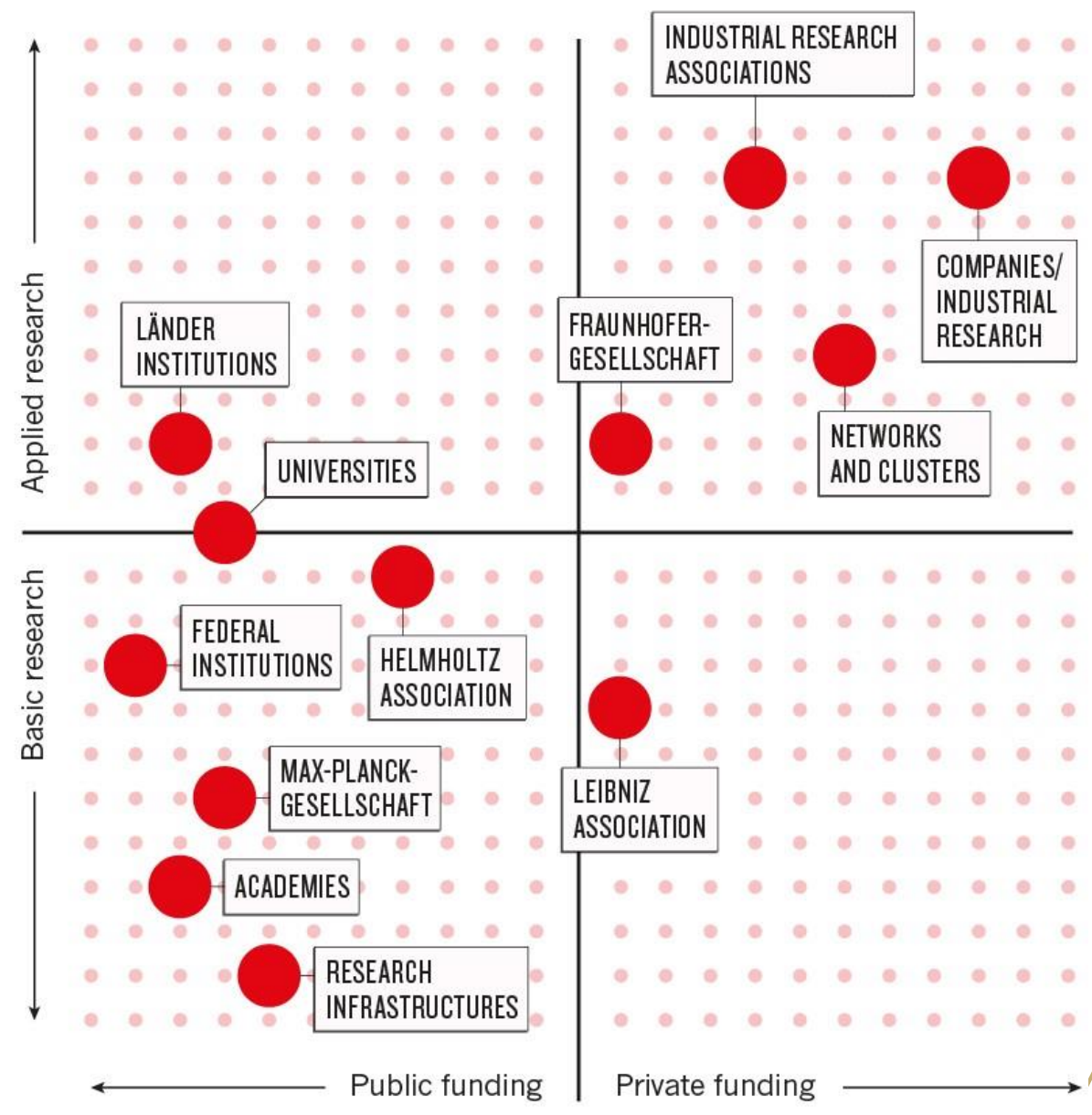

(Boytchev 2019) 


\section{MAX PLANCK GESELLSCHAFT}

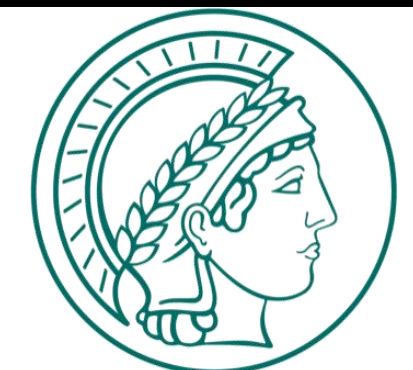

- Focuses on basic research

- 86 research institutes and facilities (5 institutes outside Germany)

- Over 23,000 employees

- More than half of the researchers come from outside Germany

- Annual budget: approx. 2.4 billion euros (2018)

- Research area: Natural sciences, Life sciences, Social sciences and the humanities

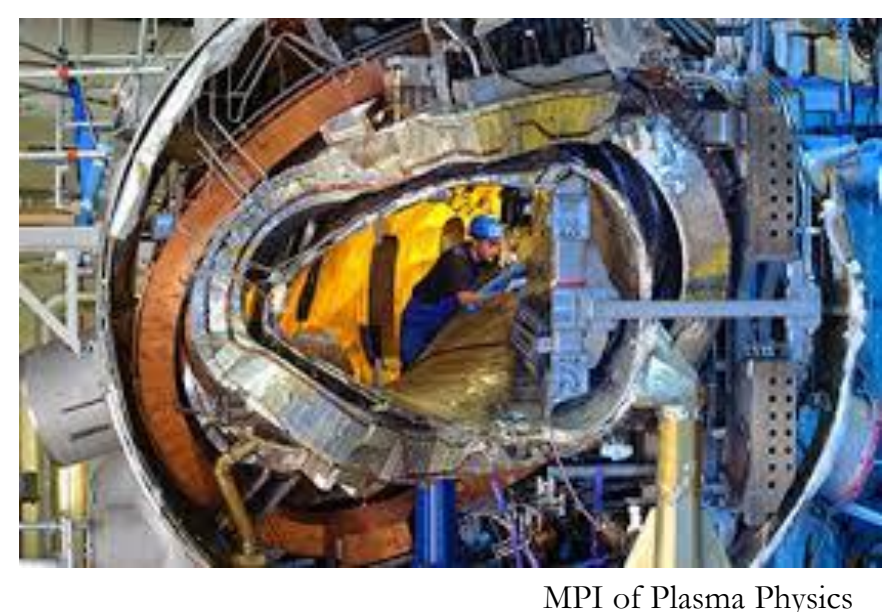

MPI of Plasma Physics

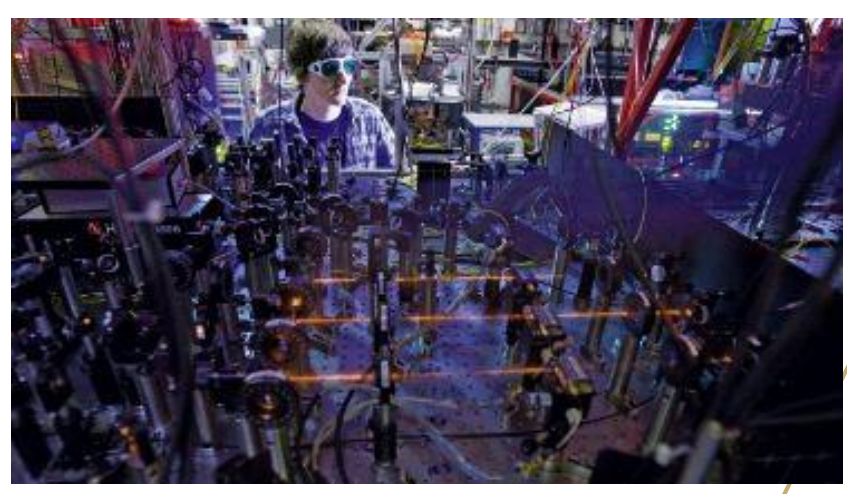

MPI of Quantum $\varnothing$ ptics

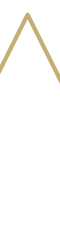

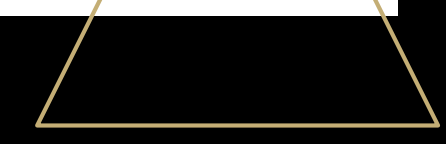




\section{Fraunhofer}

- Focuses on applied research

- Largest research organization in Europe

- Total of 72 and research units

- More than 26,600 employeesstitutes and research facilities

- Annual budget: 2.6 billion euros (2018)

- 612 patent applications (2018)

- Focuses: Health and environment, Security and protection, Communication and knowledge, Mobility and transport, Energy and resources , Production and supply of services
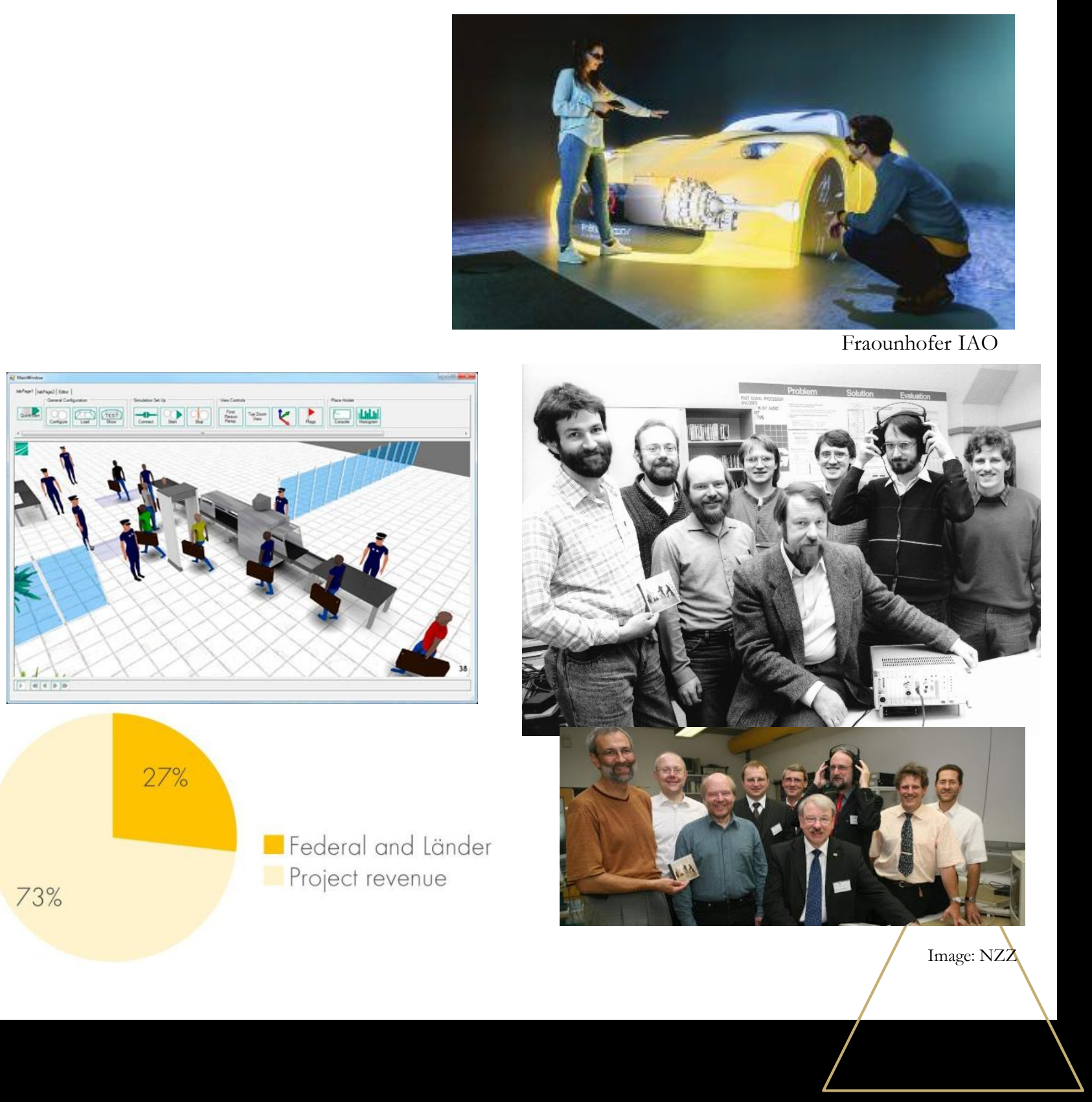


\section{Federal institutions}

- Supports the ministry's activities and provide the necessary scientific basis for government measures.

- 40 federal R\&D institutions

Deutscher Wetterdienst

- 18,600 staff, including more than 9,400 R\&D personnel Wetter und Klima aus einer Hand

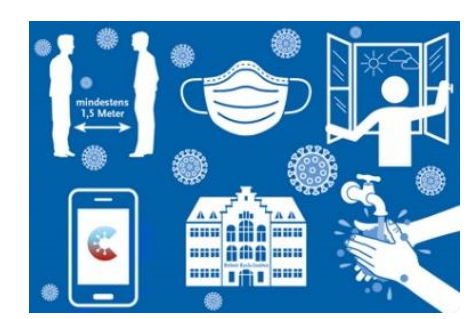

$\infty$

- Internal expenditure: 2.9 billion euros (2017)

- Research focuses:

- The impact of modern technologies

- Health and nutrition

- Mobility and urban development

- Environment, energy and climate protection

- Changed working and living conditions

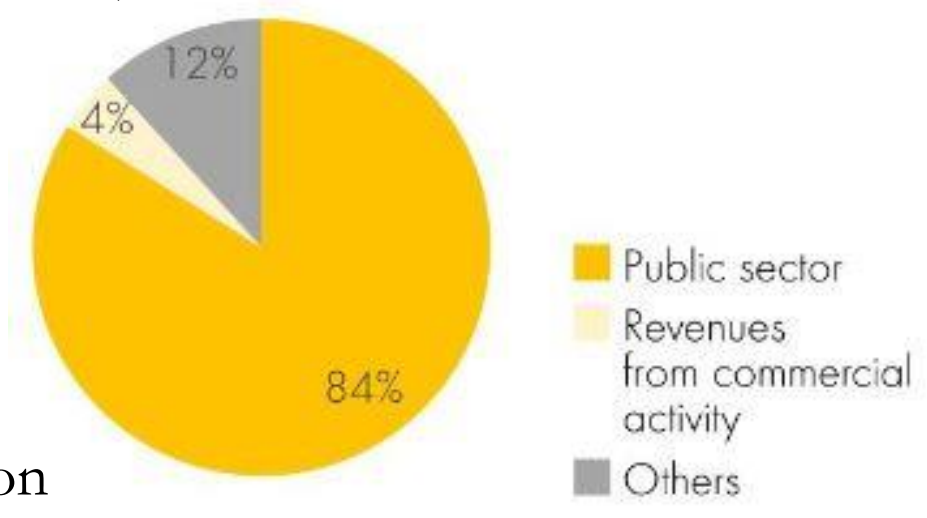

\section{BAM}

Bundesanstalt für Materialforschung und -prüfung

Revenues activity

Others

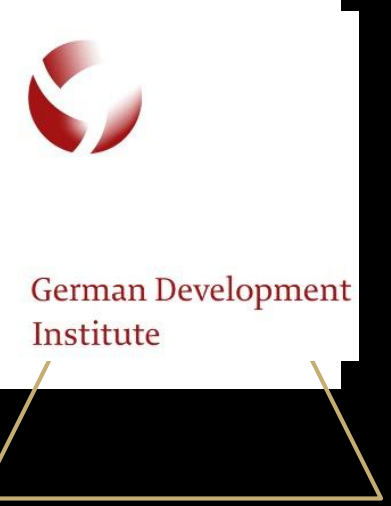




\section{Länder (state) institution}

- Research institutes that support state research activities.

- Over 160 research organisations

- 6,100 staff, including more than 2,600 R\&D personnel; among them 1,300 researchers
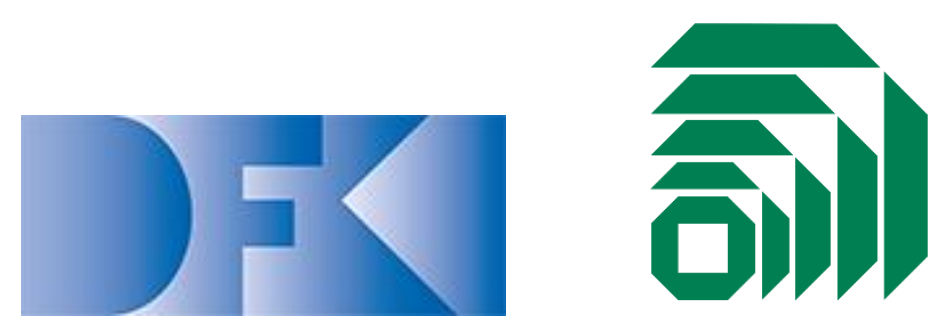

- Public sector

Revenues

from commercial

activity

activity
Others

- Internal expenditure: 520 million euros in total, including 220 million euros for R\&D (2017)

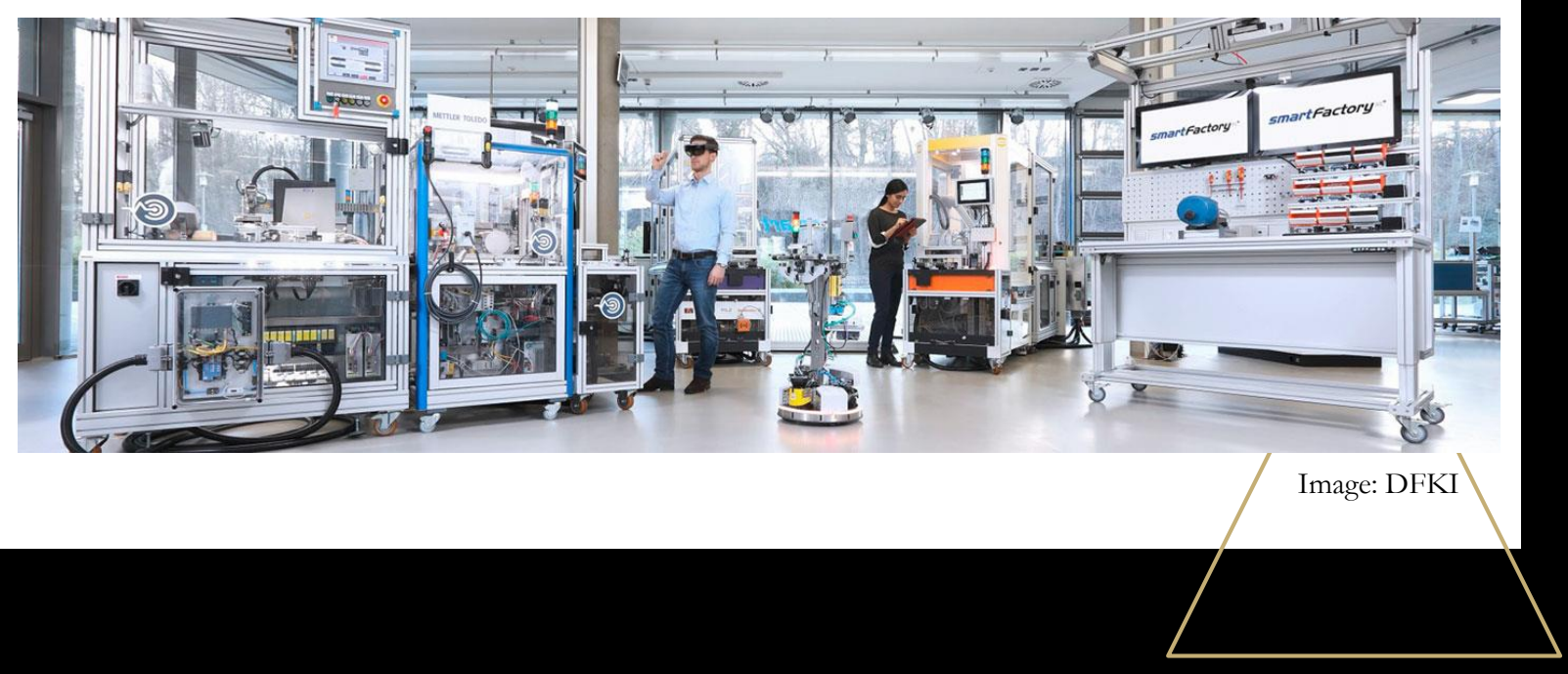




\section{Companies \& industrial research}

- Accounts for $>2 / 3$ of all R\&D funding in Germany

- Work closely with universities, universities of applied sciences and non-university research institutes

- Umbrella: Federation of German Industries (BDI)

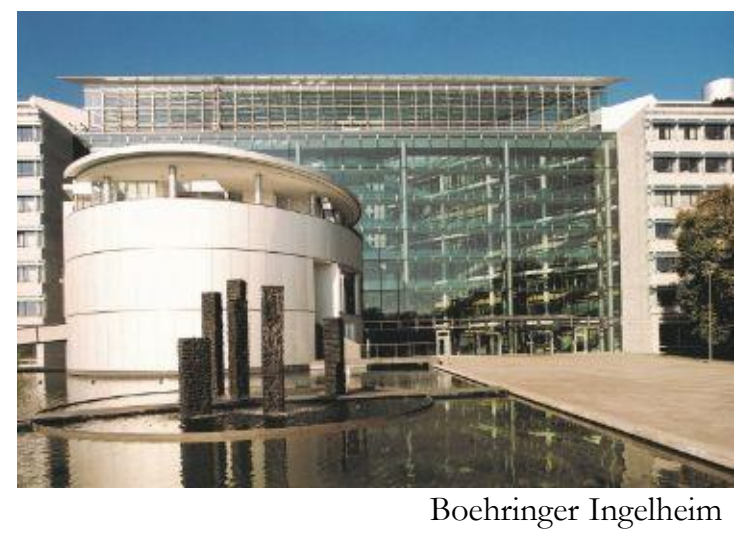

- Approx. 451,000 R\&D personnel (2018), including 236,000 researchers (2016)

- Annual budget for R\&D: approx. 72.1 billion euros (2018)

Companies with the highest R\&D spending in Germany in $2017 / 18$ (in billion euros:

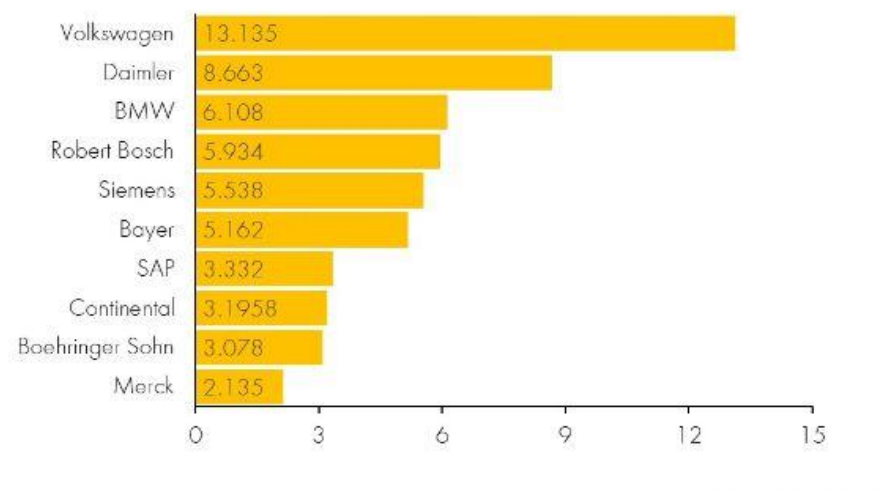




\section{Cooperation between industry and research}

- Contract research for industry carried out by universities and non-university research institutions

- Joint staffing and funding of research projects

- Industry-funded research groups

- Donations and sponsorship for specific R\&D institutes

- Establishment of endowed professorships by companies

- Jointly funded research structures or institutes

Public sector Industry

International

- New collaborative models in networks, clusters or public-private partnerships/research campuses 


\section{Industrial research associations}
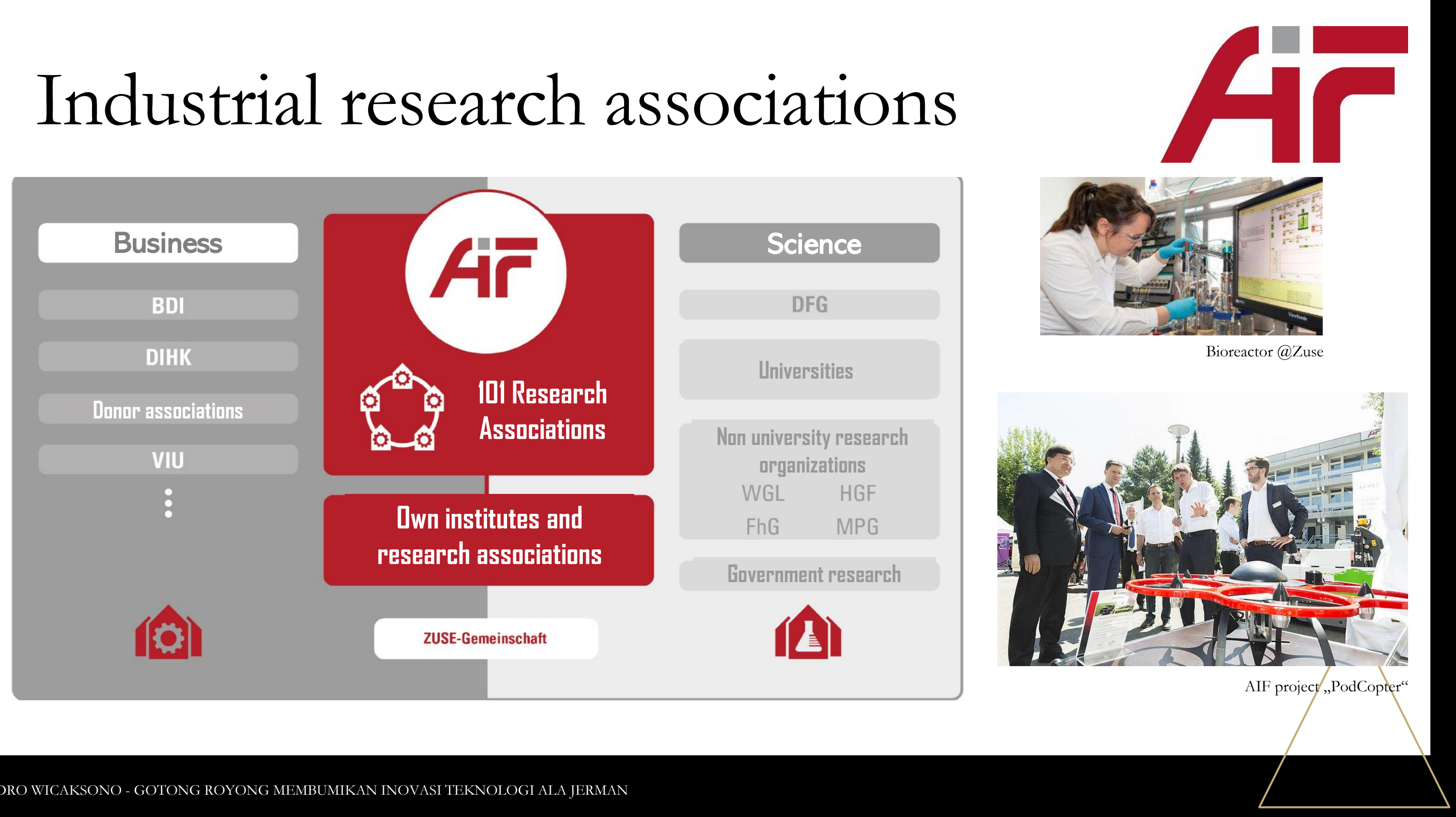


\section{III. Implementation of Triple-Helix Innovation in Germany}




\section{Triple Helix Innovation Models}

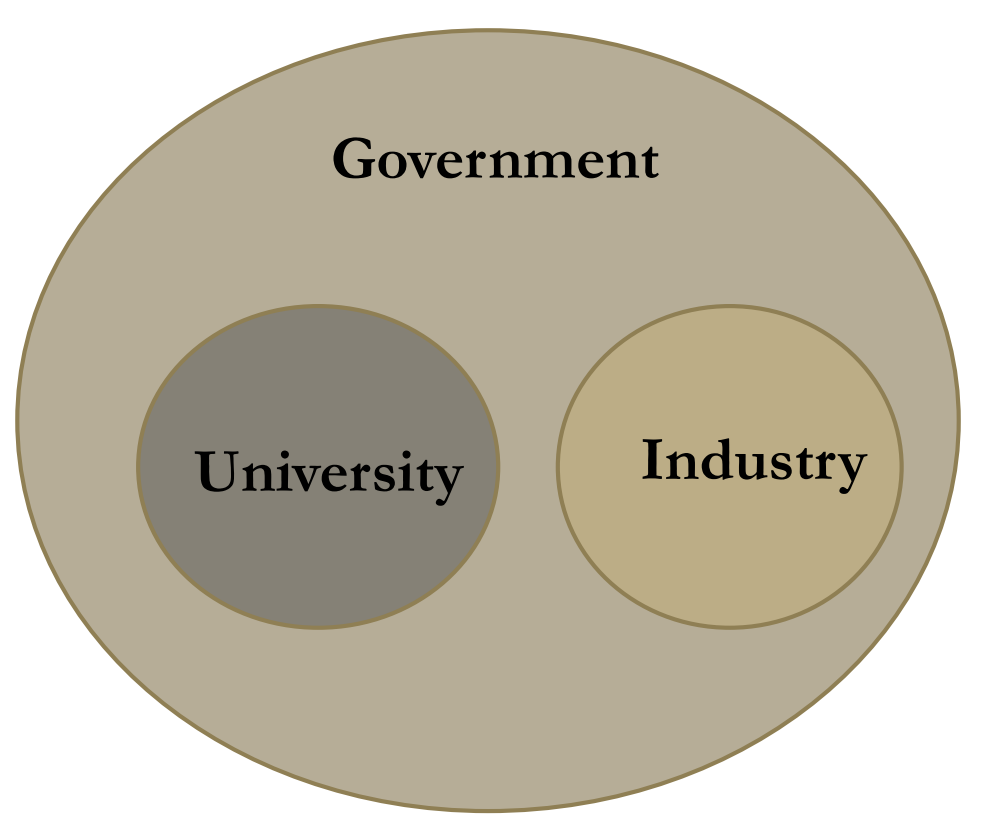

Model 1

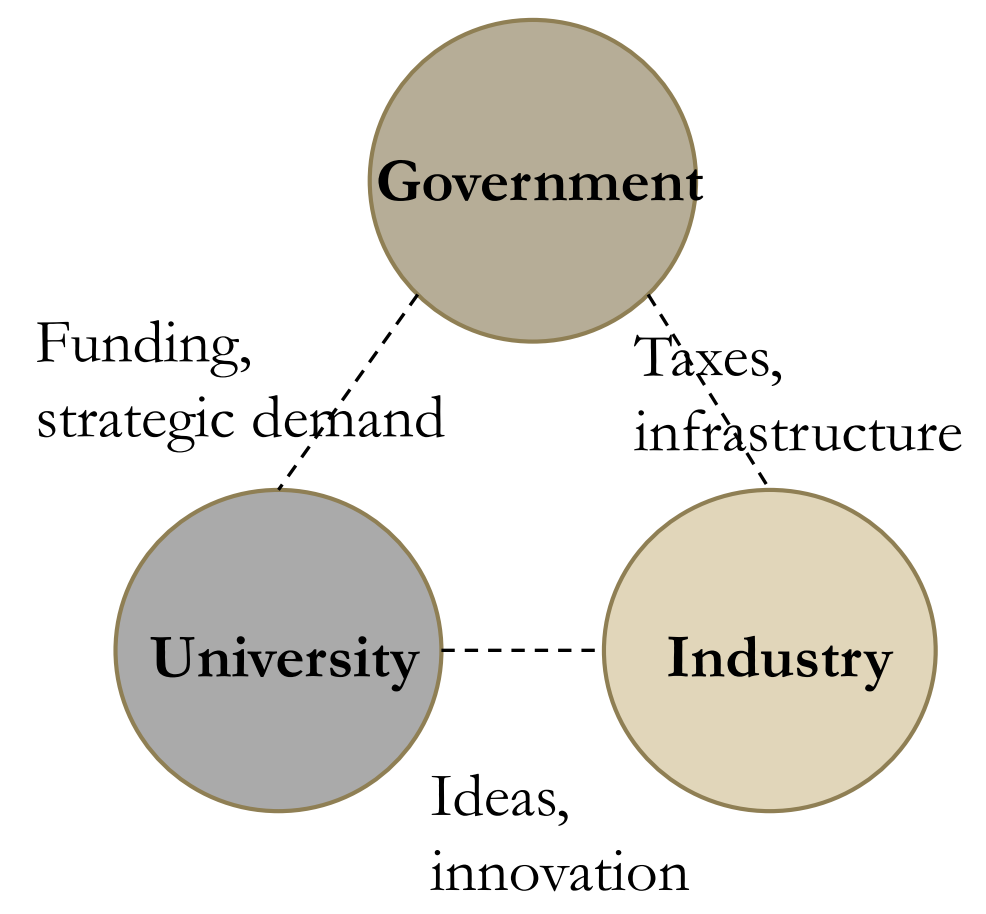

Model 2

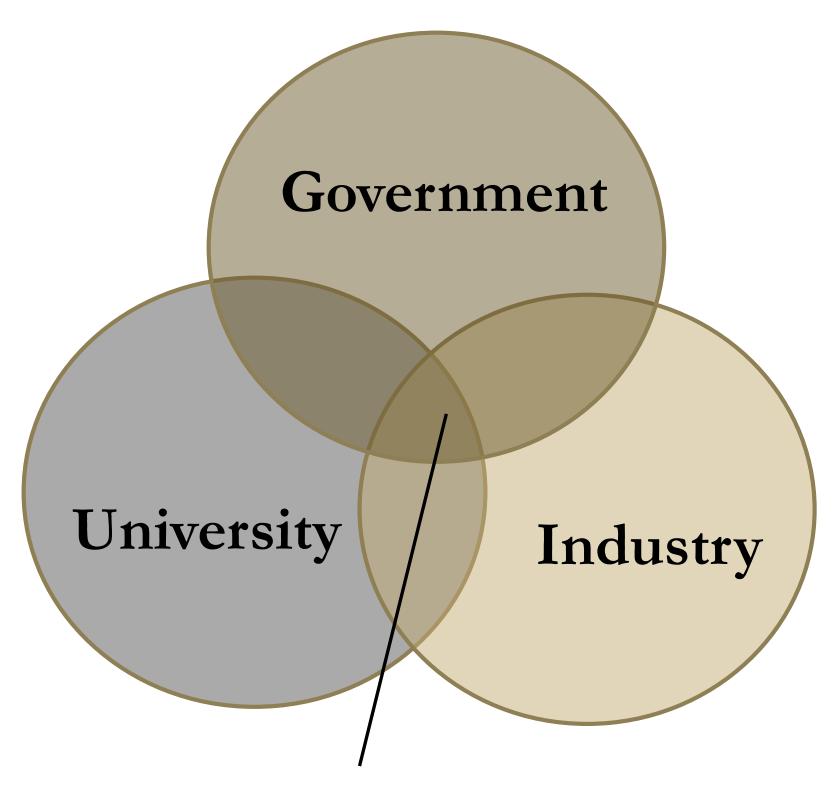

Integrated innovaton environment

Model 3

(Etzkowitz \& Leydesdorff 2000) 


\section{Triple Helix Implementation in Germany}

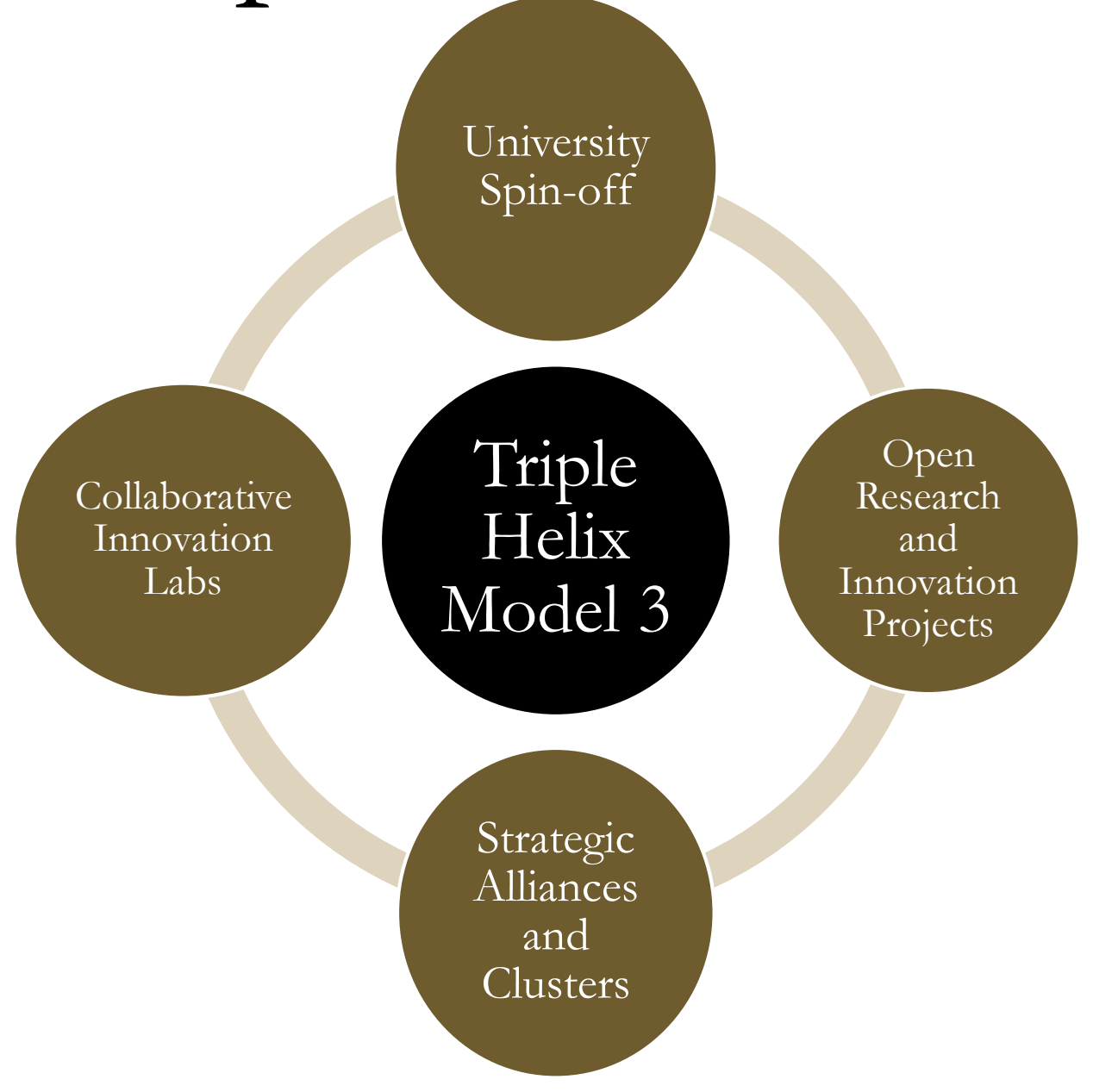




\section{1: University Spin-Off}

| Bundesministerium

für Wirtschaft
und Technologie

eXIST

Existenzgründungen aus der Wissenschaft

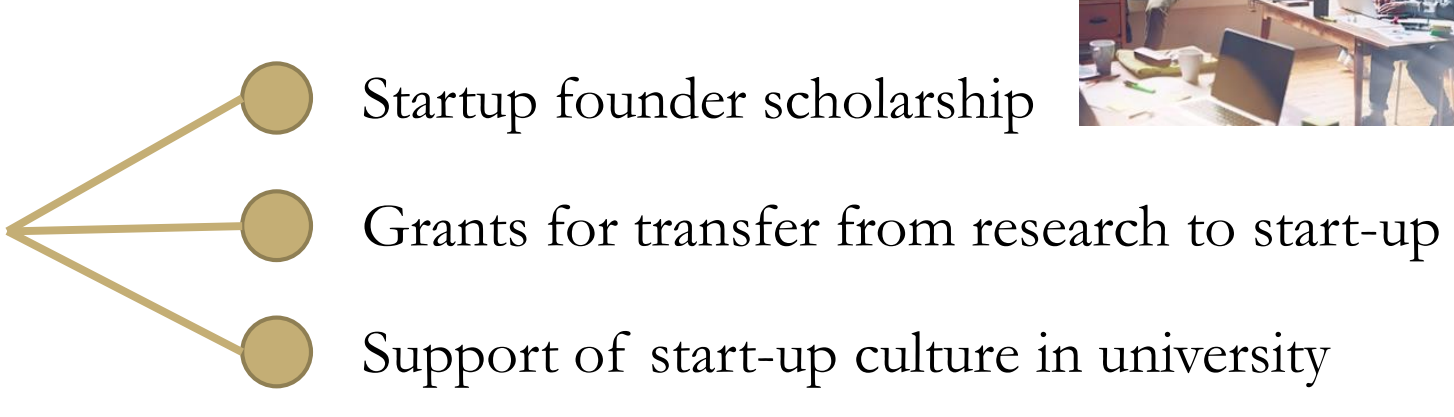

Transformation of University Program

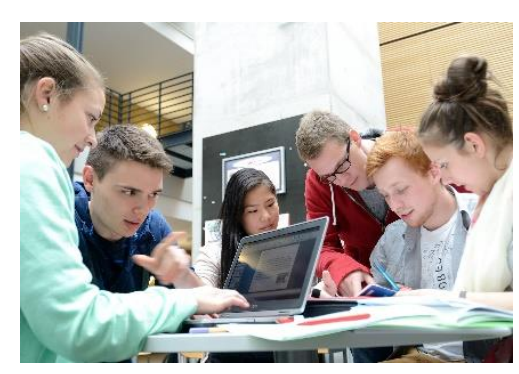

- Integration of startup programs in university's curricula

- Startup activities substitutes courses credits
Example of successful startups

\&

OPENEXPERIENCE

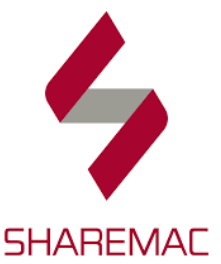

P. PHYSEC

vilisto

einfach Wohlfühlklima

NosoEx 


\section{2: Open Research and}

Innovation Projects

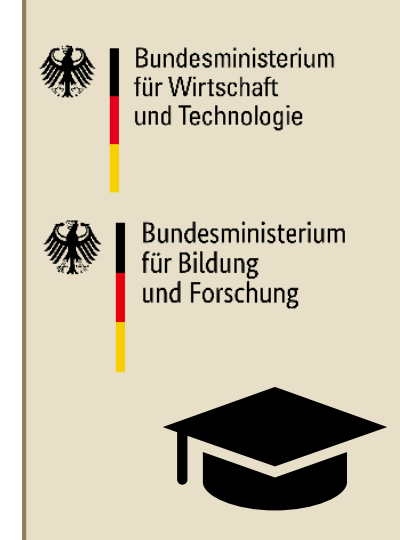

University $100 \%$

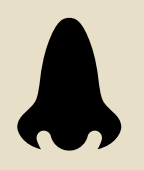

$\mathrm{SME}$

$50-60 \%$
Total Funding:

$\mathbf{6 0 - 7 0 \%}$ of project costs

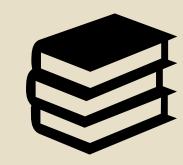

Applied research

organization

$80-90 \%$

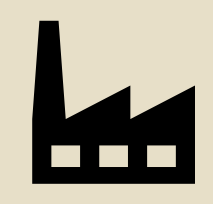

Large enterprise $30-40 \%$
Project Examples

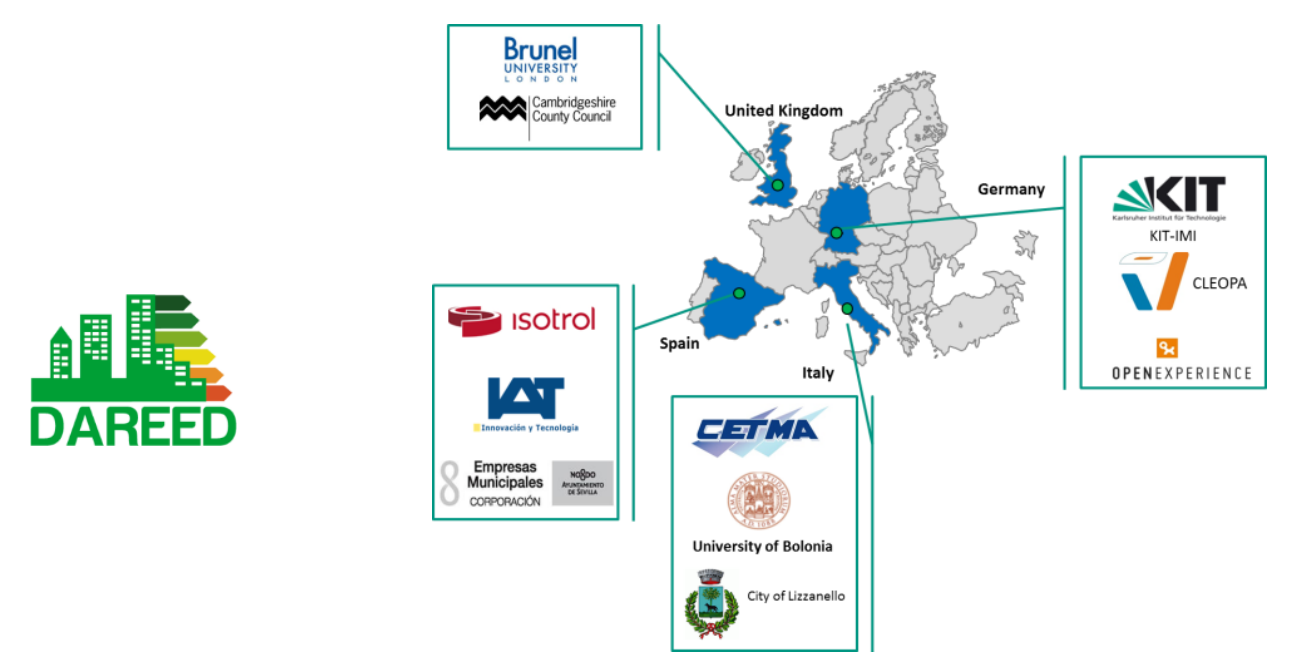

Delf

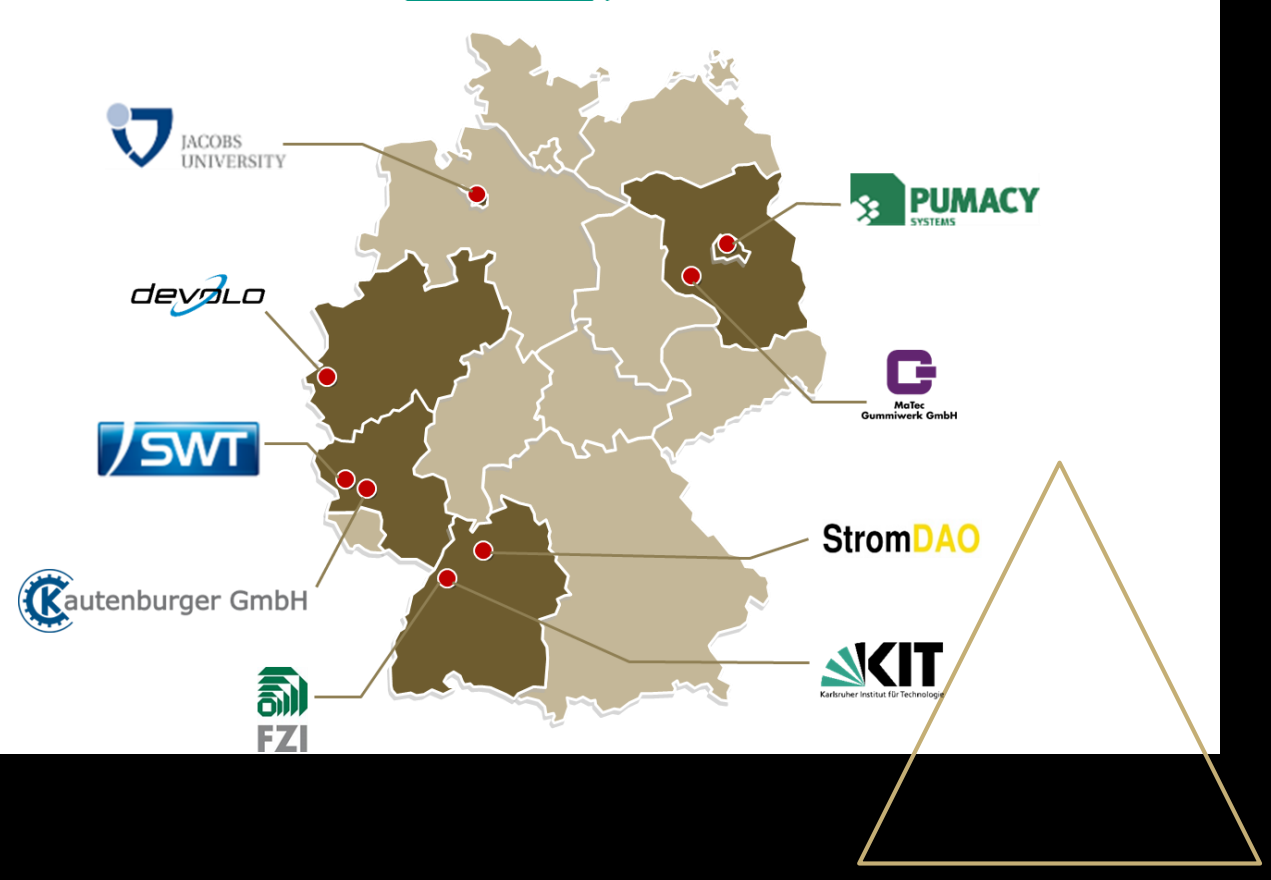




\section{3: Strategic Alliances and Innovation Clusters}

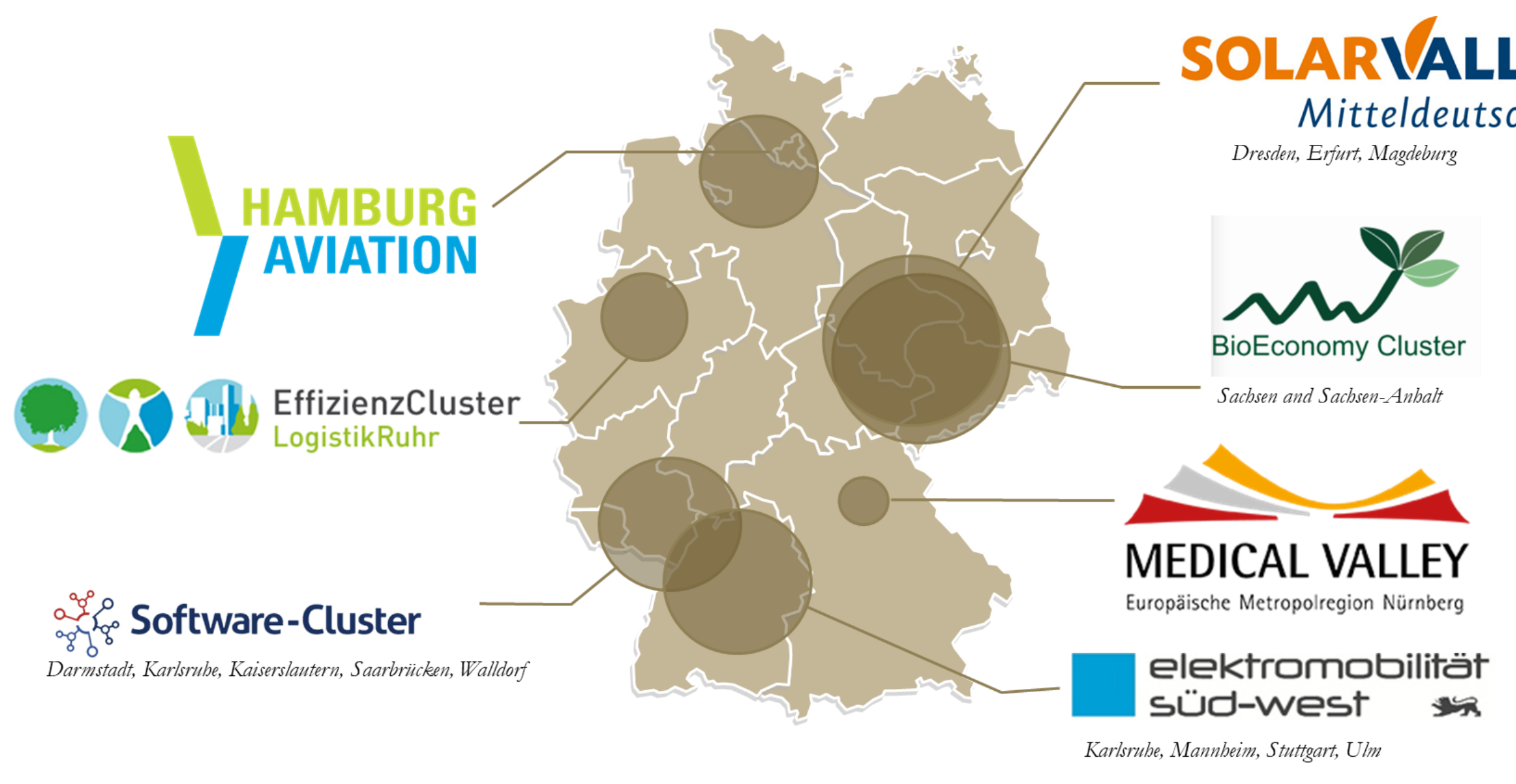




\section{4: Collaborative innovation labs:}

\section{Industry 4.0 implementations}

Testbeds

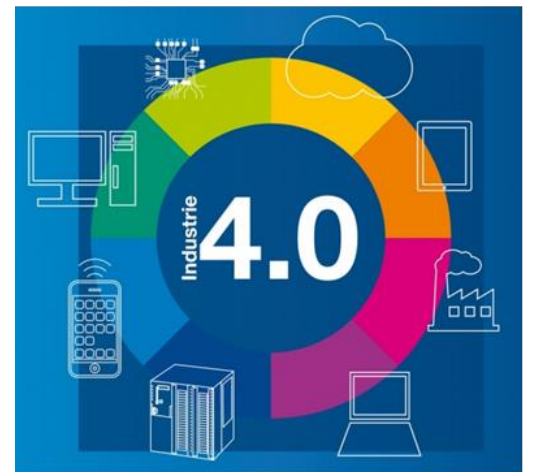

- Small and Medium Enterprises

University Research

Research Outside University

Large Companies

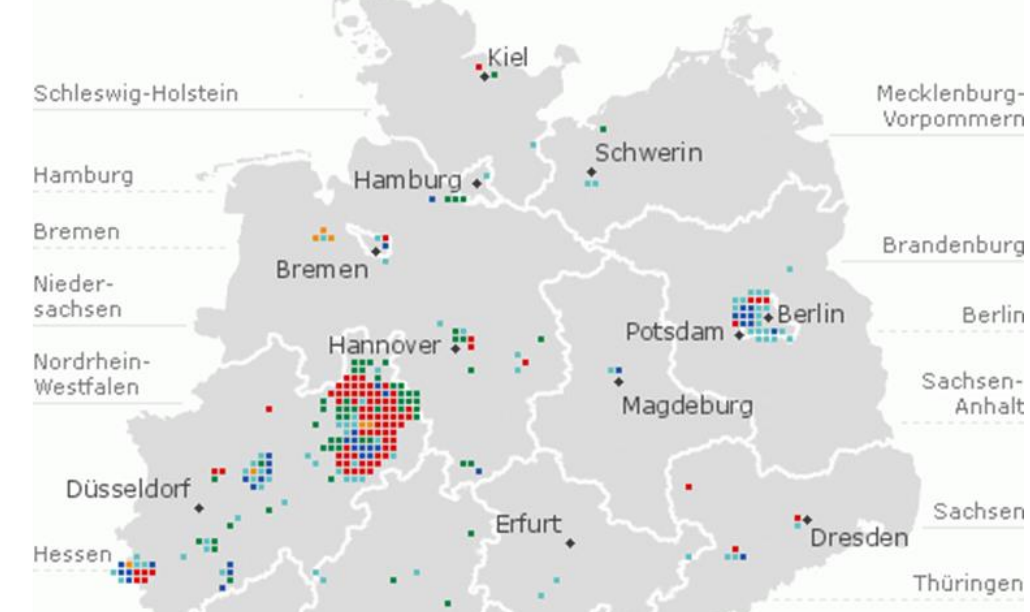

\begin{tabular}{l} 
Rhe \\
Pfal \\
\hline Saa \\
\hline
\end{tabular}

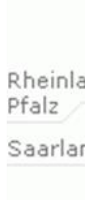

Baden-
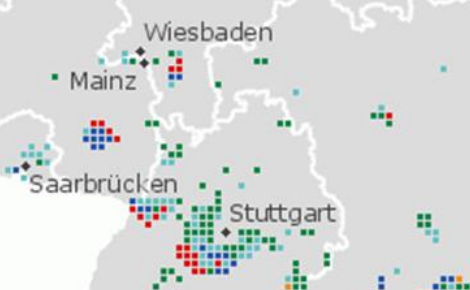

Bayern
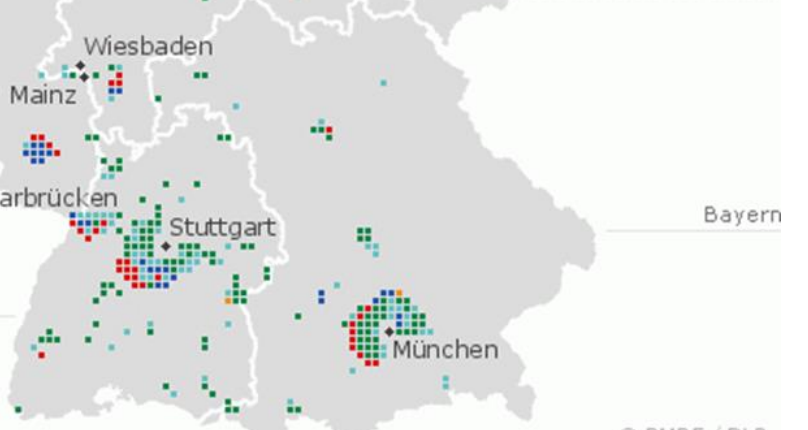

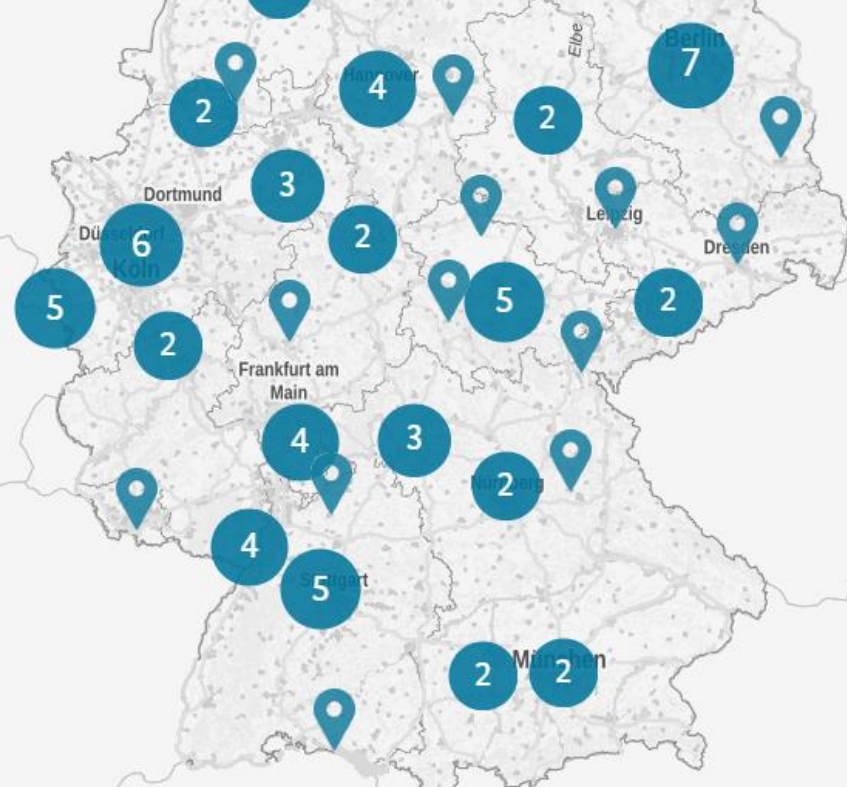




\section{Triple Helix Model 3 Requires Transformation of All Parties}

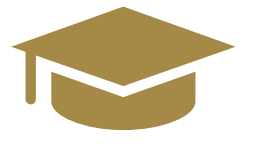

From teaching to research and innovation university

From closed to open innovation, from one-man show to ecosystem of global village

From top-down to bottom-up policy making 


\section{Indonesia: Quintuple Helix?}

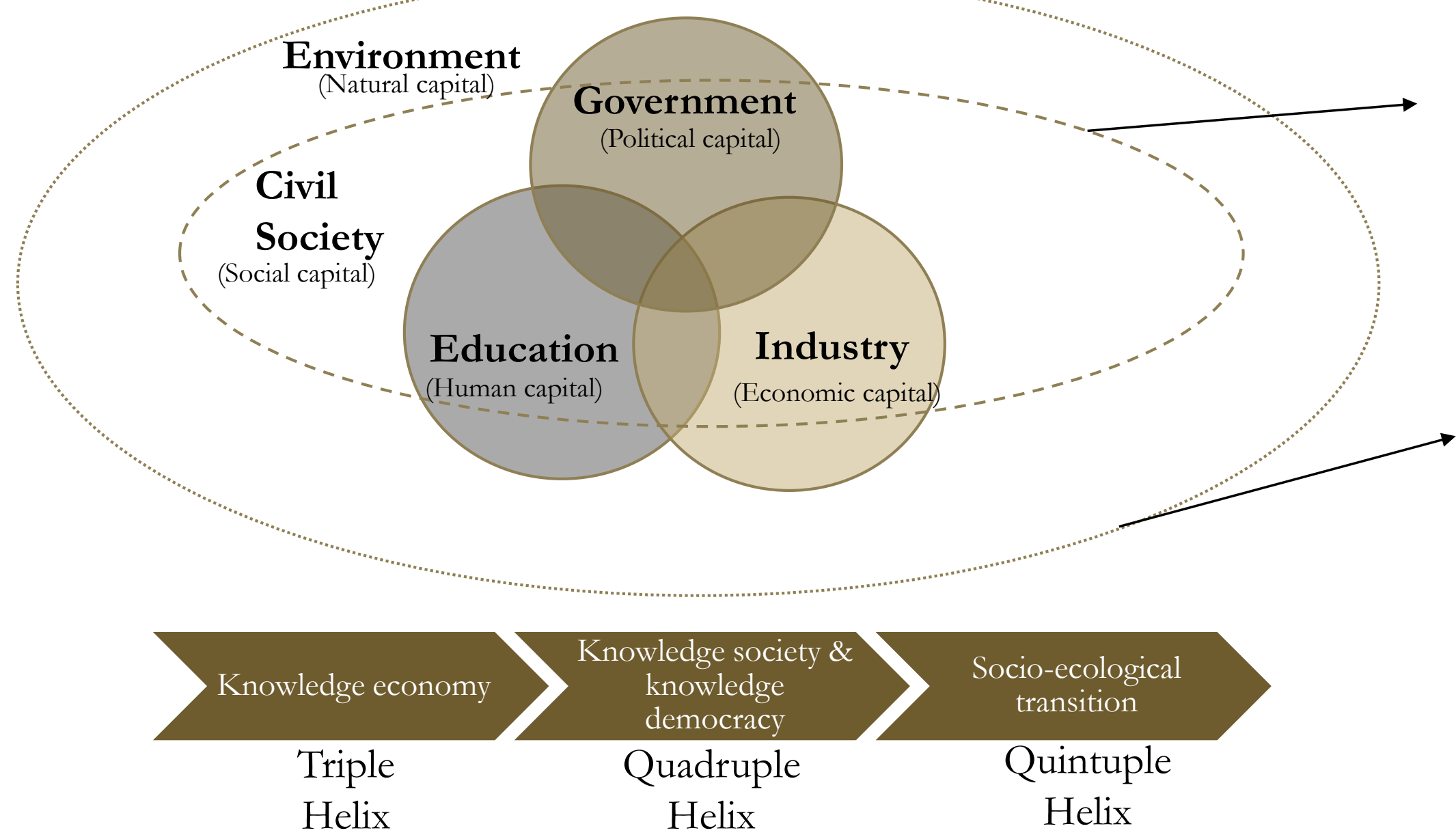

Collective society

(Physical and virtual), "gotong royong“"

Biodiversity,

Natural resources

protection

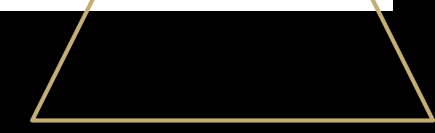




\section{Types of Projects}

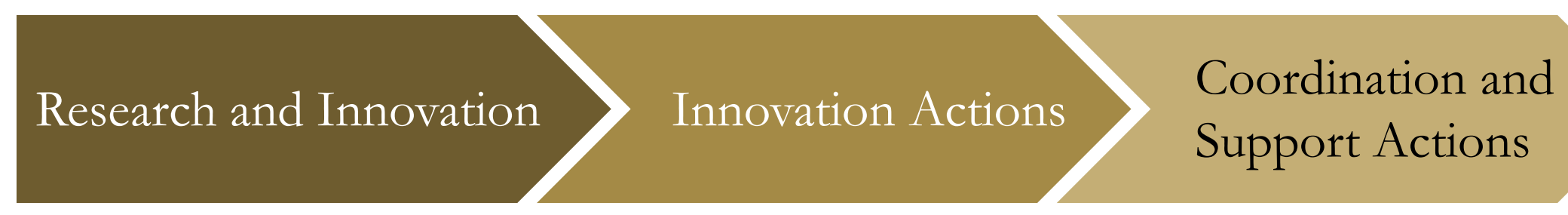

New knowledge, feasibility of improved technologies

Testing, demonstrating, piloting, large-scale product validation, and market replication.
Standardisation, dissemination, awarenessraising and communication, networking 


\section{Project Example}

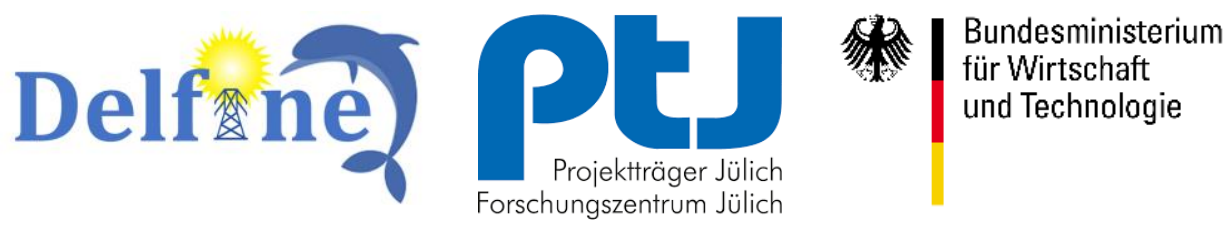

- Objective: Development of Demand Response System for manufacturing

- Forecast models for power consumption and decentralized energy generation systems.

- Dynamic electricity price models

- Semantic middleware for data communication between energy producer and consumer

- Integration of price signals into production planning for efficient use of resources.

- Transfer of planning data from the industry to the energy producer / network operator, which includes the implementation of further demand-response readiness analyzes.

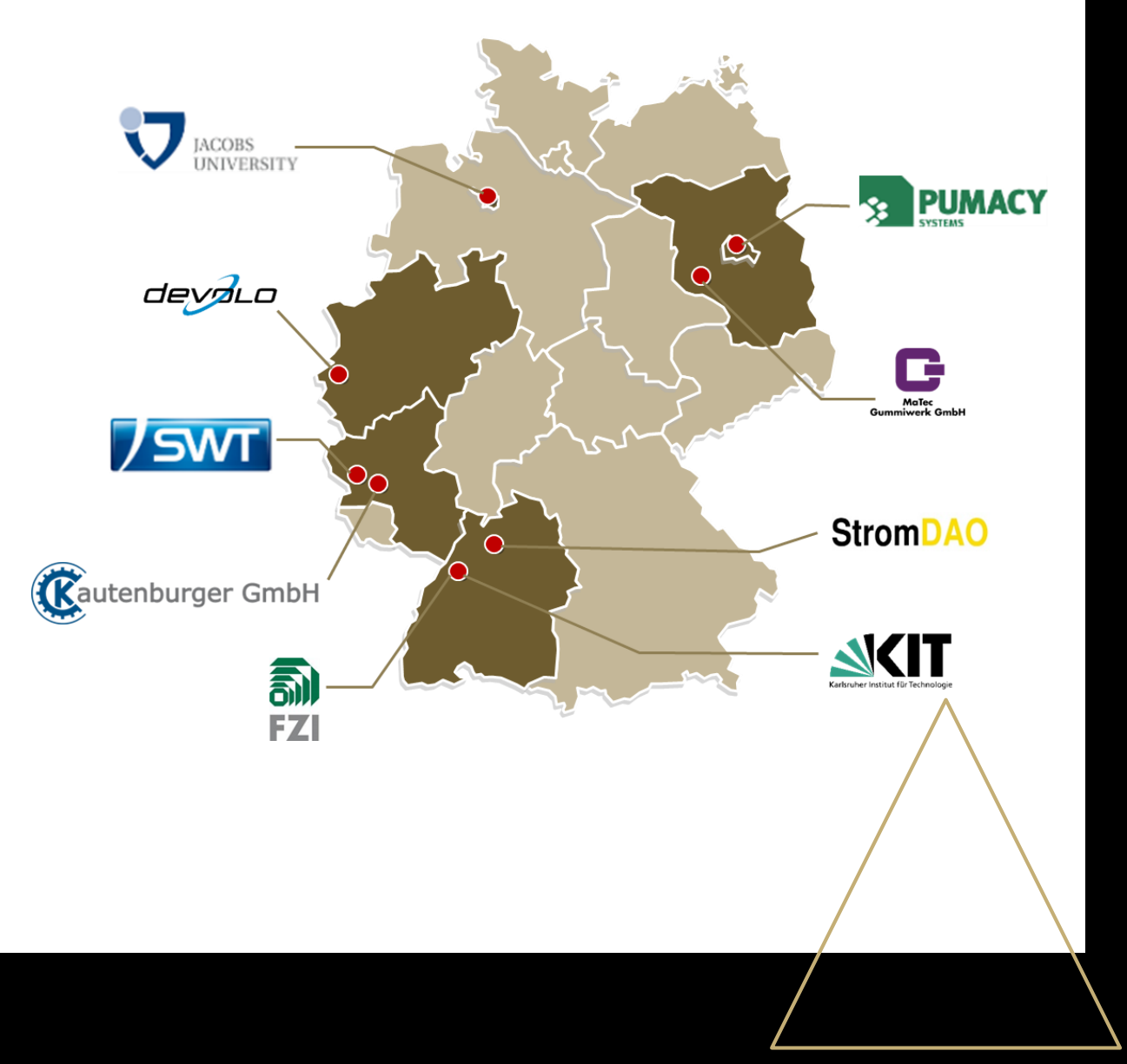




\section{ecobalance}

- Digital twin containing machine learning to identify energy consumption profile for each industrial machine and process

- Forecasting of costs and power consumption of customized product

- Optimization model for production planning and control with power peak avoidance, having lowest costs, and on-time lead time

- Cloud-edge architecture

- Applied in a metal processing SME

- Budger: $€ 600000$
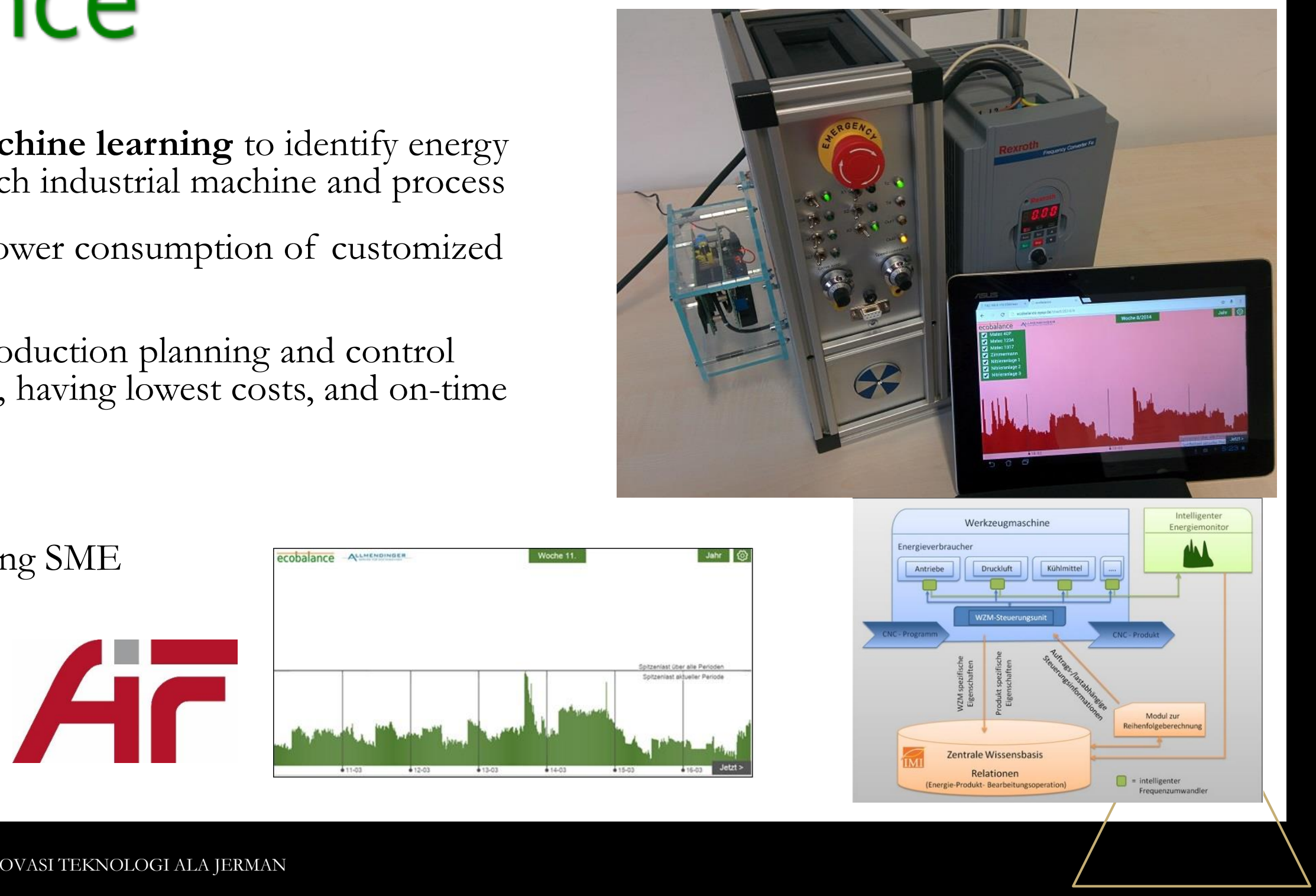


\section{Workpackage Dependencies}

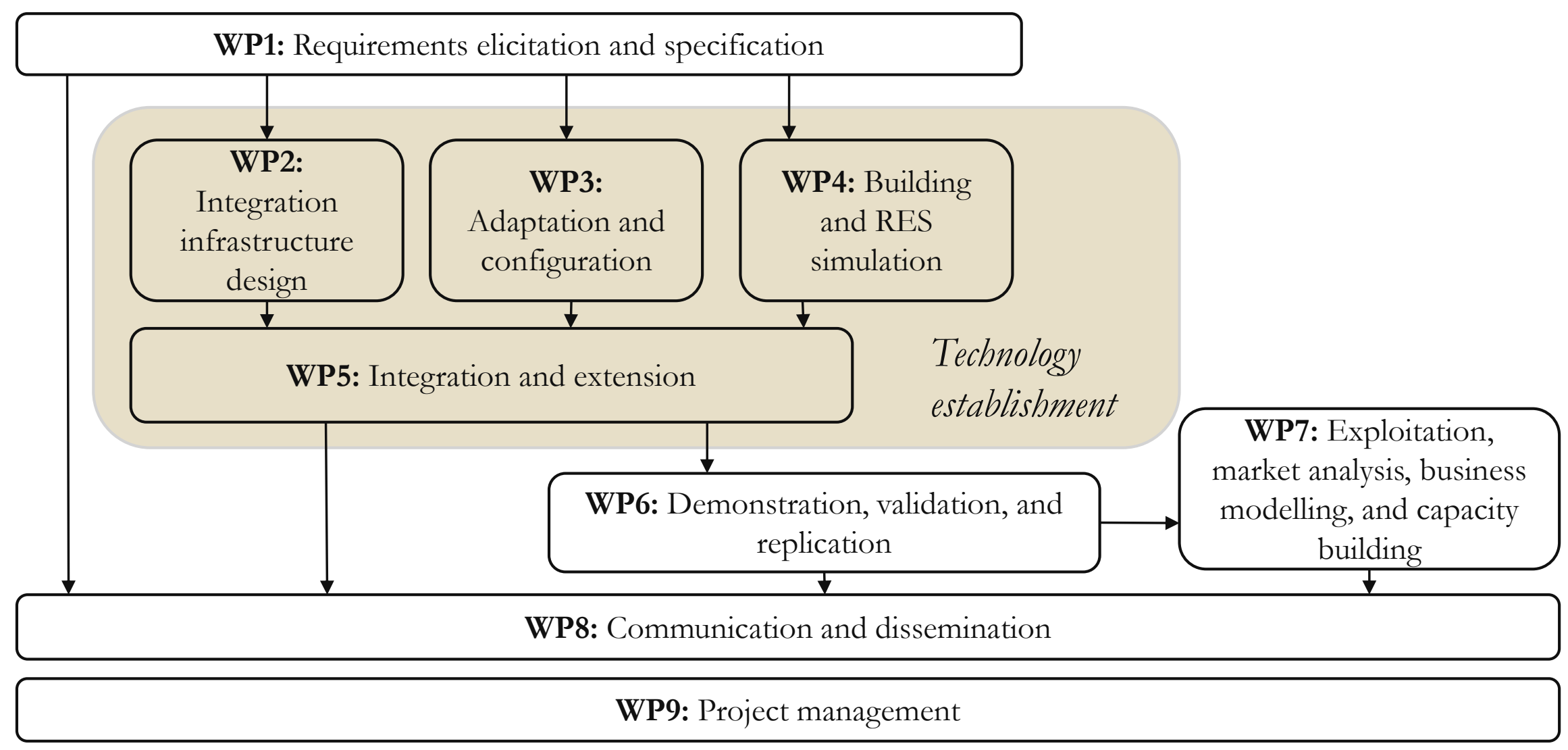




\section{Project Organization Structure}

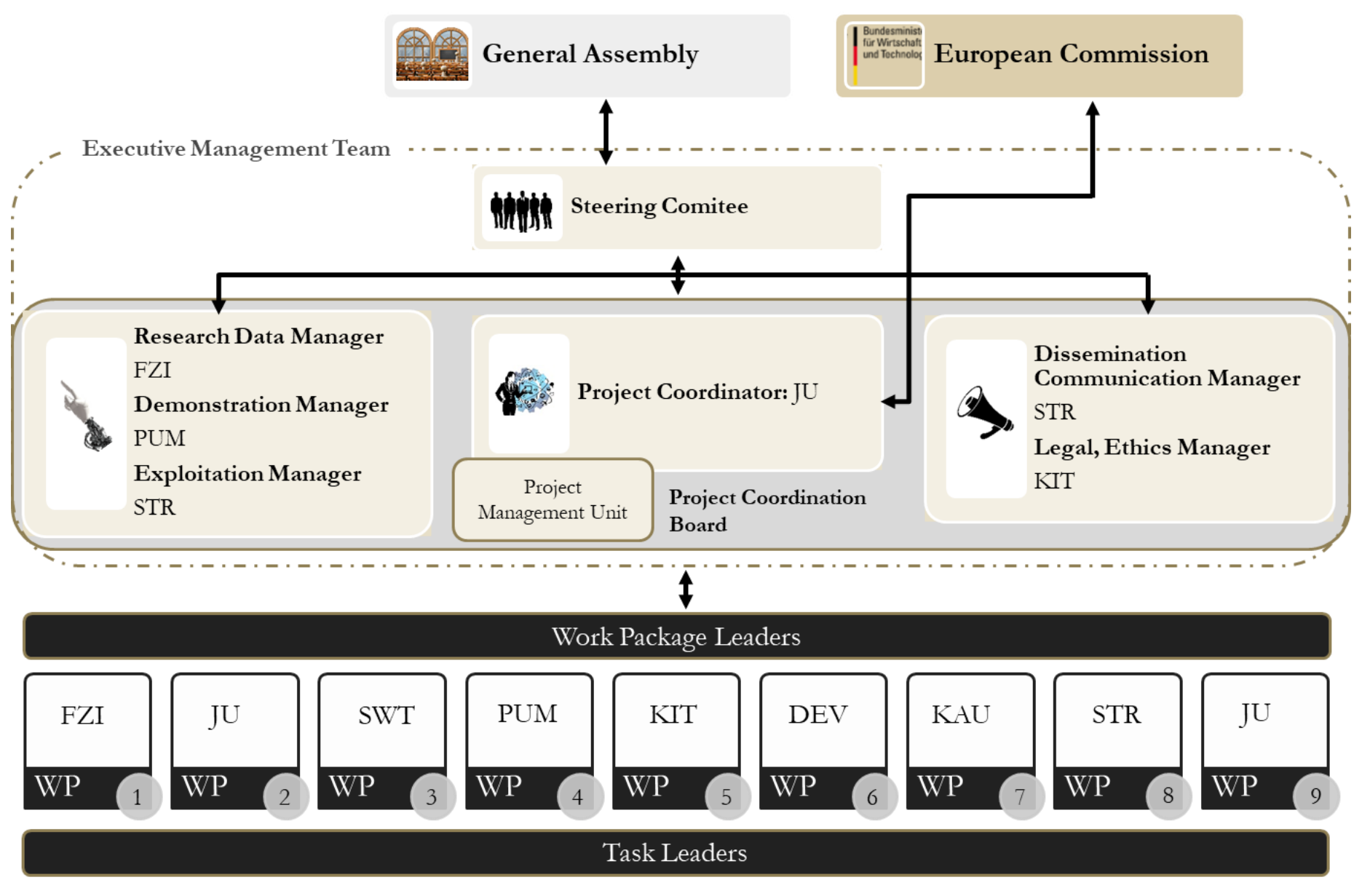




\section{IP Management}

- Background IP: all Intellectual Properties belonging to or controlled by either Party,

- (i) developed, conceived, obtained or acquired prior to the agreement/ project or

- (ii) developed, conceived, obtained or acquired independently of the agreement/project or not as part of the approved project statement.

- Foreground IP: means any Intellectual Property arising from the project; 


\section{Background IP Examples}

4.1 .1 .5 Rele
Publications

McGlinn, K; Weise, M.; Wicaksono, H. (2016): Towards a Shared Use Case Repository to support Building Information Modelling in the Energy Efficient Building domain. In CIB W78 Conference, Queensland University

2. Wicaksono, H.; Krahtova, P.; Häfner, P.; Rogalski, S. (2015): Methodology to Develop Ontological Building Information Model for Energy Management System in Building Information Phase, Knowledge Discovery, Knowledge Engineering and Knowledge Management Communications in Computer and Information Science,

3. Wicaksono, H.; Rogalski, S.; Jost, F.; Ovtcharova, J. (2014): Energy Efficiency Evaluation and Optimization in in Accounting, Finance and Management, John Wiley and Sons, 2014, pp 1099-1174 -

Wicaksono, H.; Dobreva, P(Krahtova).; Häfner, P.; Rogalski, S. (2013): Ontology Development towards Expressive and Reasoning-enabled Building Information Model for an Intelligent Energy Management System 5th International Conference Knowledge Engineering and Ontology Development, 19-22 September 2013.

5. Hâfner, P.; Häfner, V.; Wicaksono, H; Ovtcharova, J. (2013): Semi-automated Ontology Population from Building Construction Drawings, 5th International Conference Knowledge Engineering and Ontology

Product and Services

ontoCAD is a tool to generate instances and to populate ontologies by interpreting $2 \mathrm{D}$ sketches and extracting their semantic which was initially developed in KnoHolEM project. ontoCAD allows the user to decide the corresponding semantics any geometrical shapes in a $2 D$ sketches. ontoCAD contains a pattern matching be adapted and further developed for the data uplift into ontology. Knowledge manager is a soffware that was initially developed in DAREED project. Knowledge manager is responsible to connect a high level data abstraction which is represented using ontologies to heterogeneous
data sources It allows the data-consuming applications to access data without knowing the location of the data data sources. It allows the data-consuming applications to access data wer
sources. The knowledge manager provides API equipped with a user authentication system so that any authorized applications can access the managed data

4.1.1.6 Previous projects and activities re
1. SWIMing (EU-H2020-CSA) as WP Leader SWIMing has developed guidelines and best practices for generating open and accessible building data and
publishing that data to the web. And to raise awareness of experts in academia and industry towards the benefits of using open data standards and ontologies for building lifecycle energy management The guidelines will help the construction of ESPRESSINDO knowledge graph.

2. DAREED (FP7-SMARTCITIES-2013) as Technical Coordinator and WP Leader DAREED aims at delivering an IT service oriented platform to support decision-making and foster energy granting the possibility to generalize results and ensuring sustainability throughout Europe. The project targets decision-makers and energy providers at local level and is seeking to support them to overcome technological, financial and knowledge barriers and adopt new strategies for improving the energy performance. DAREED developed methods and tools for data integration using semantic web technologies and for ensuring the quality

3. KnoHoIEM (FP7-2011-NMP-ENV-ENERGY-ICT-EeB) as Technical Coordinator and WP Leader The KnoholEM main objective is to improve energy efficiency in public buildings trough progressive and intelligent knowledge modeling approach

- Alignment of the information model with standards (IFC-OWL mapping, CAD/FC to OWL),

- Development of an expressive ontology knowledge base as the integration point in the system architecture and allowing reasoning

- 3D visualization of the building environment for the final user

- Data mining for extracting the energy consumption pattern in order to detect energy inconsistent

performance and to generate energy consumption predictions

- Automated ontology population concept and tool (ontoCAD) that go beyond the state of the at

Some of the KnoHolEM results will be exploited and adapted for the ESPRESSINDO projects: a. ontology development for the development of semantic middleware,

c. OntoCAD for the data uplifiting into ontology.

4. KlimaRA (industrially funded project)

As coordinator of this project KIT has been assigned to develop a knowledge based energy efficiency management and optimization for historical city hall in the state Baden-Württemberg by employing a building management system that gathers the energy, environment and occupancy data. The project utilizes ontolog as representation of the knowledge base and data mining to extract the usage pattern from sensor data. 


\section{Conclusions}

- Open innovation can shorten innovation funnel

- Open innovation requires ecosystems: triple helix model 3

- Triple Helix Model 3 requires transformation of all parties

- Collaborative open innovation projects require clear governance structure and communication flow

- Collaborative open innovation projects require data and intellectual property right management 


\section{Thank You}

- LinkedIn

https://www.linkedin.com/in/hendrowicakso no/

\section{Facebook}

https://www.facebook.com/hendro.wicakson o.9

Email

h.wicaksono@jacobs-university.de hendro.wicaksono@green-indonesia.com

Homepage

http://indeed.user.jacobs-university.de/ 